\title{
Sources and fate of terrestrial dissolved organic carbon in lakes of a Boreal Plains region recently affected by wildfire
}

\author{
D. Olefeldt ${ }^{1}$, K. J. Devito ${ }^{2}$, and M. R. Turetsky ${ }^{1}$ \\ ${ }^{1}$ Department of Integrative Biology, University of Guelph, Guelph, ON N1G 2W1, Canada \\ ${ }^{2}$ Department of Biological Sciences, University of Alberta, Edmonton, AB N6A 5B7, Canada
}

Correspondence to: D. Olefeldt (dolefeld@uoguelph.ca)

Received: 3 March 2013 - Published in Biogeosciences Discuss.: 2 April 2013

Revised: 23 August 2013 - Accepted: 28 August 2013 - Published: 2 October 2013

\begin{abstract}
Downstream mineralization and sedimentation of terrestrial dissolved organic carbon (DOC) render lakes important for landscape carbon cycling in the boreal region. The chemical composition of terrestrial DOC, the downstream delivery of terrestrial DOC and its processing within aquatic ecosystem may all be influenced by climate change, including increased occurrence of wildfire. Here, we assessed composition and lability (during both dark- and UV incubations) of DOC from peatland groundwater and mineral soil groundwater, and from shallow lakes within a peatland-rich region on the Boreal Plains of western Canada that was recently affected by wildfire. Wildfire was found to increase aromaticity of DOC in peat pore water above the water table, but had no effect on the concentrations or composition of peatland groundwater DOC or mineral soil DOC. Using a mixing model we estimated that on average 98 and $78 \%$ of terrestrial DOC inputs to the lakes in fine- and coarse-textured settings, respectively, originated from peatland groundwater sources. Accordingly, lake DOC composition reflected primarily a mixing of peatland and mineral soil groundwater sources, with no detectable influence of the recent wildfire. Lake and peatland DOC had low biodegradability, lower than that of mineral soil DOC. However, both mineralization and sedimentation of peatland DOC increased substantially during UV incubations through selective removal of aromatic humic and fulvic acids. Similar shifts in DOC composition as observed during the UV incubations were also observed across lakes with longer water residence times. The mixing model estimated that on average $54 \%$ (95\% confidence interval: 36-64\%) of terrestrial DOC had been removed in lakes as a result of mineralization and sedimentation. Meanwhile, the reduction in absorbance at $254 \mathrm{~nm}$
\end{abstract}

was $71 \%(58-76 \%)$, which suggests selective removal of aromatic DOC. Hence, incubation results, patterns of DOC composition among lakes and mixing model results were consistent with significant within-lake removal of terrestrial DOC through UV-mediated processes. Selective removal of highly aromatic DOC through UV-mediated processes implies that organic sources that are considered stabile in terrestrial ecosystems can be readily mineralized once entering aquatic ecosystems. Together, our results suggest that regional characteristics (climate, surface geology and lake morphometry) can prevent wildfire from causing pulse perturbations to the linkages between terrestrial and aquatic $\mathrm{C}$ cycling and also regulate the processes that dominate withinlake removal of terrestrial DOC.

\section{Introduction}

Lakes act as reactors where dissolved organic carbon (DOC) leached from terrestrial ecosystems is mineralized, transformed and sedimented (Tranvik et al., 2009). As a result, lakes accumulate carbon (C) in sediments while simultaneously being net sources of $\mathrm{CO}_{2}$ to the atmosphere (Sobek et al., 2005; von Wachenfeldt et al., 2008). Lakes are believed to play a particularly significant role for the $\mathrm{C}$ balance of the boreal region, since they cover a large fraction of the landscape and receive DOC inputs from terrestrial ecosystems that often are equal in magnitude to long term carbon accumulation rates in soils (Prairie, 2008; Olefeldt et al., 2013a). It is now accepted that a large fraction of terrestrially exported DOC is removed through within-lake processes before reaching the ocean (Algesten et al., 2004; 
Weyhenmeyer et al., 2012). Both microbial and ultraviolet (UV) processes contribute to this removal, but act selectively on different types of DOC compounds (von Wachenfeldt et al., 2008; Benner and Kaiser, 2011). An improved understanding of the overall and relative contribution of these processes for within-lake removal of terrestrial DOC as a function of catchment and lake characteristics is necessary in order to anticipate implications for linkages between terrestrial and aquatic $\mathrm{C}$ cycling associated with climate change, including pulse perturbations such as wildfire.

The chemical composition of DOC differs among terrestrial sources, both within and between ecosystems. Leachates from live vegetation and fresh litter have a high contribution of low-molecular-weight (LMW) carbohydrates, while leachates from humified organic soils, including peat, often are dominated by highly aromatic high-molecular-weight (HMW) humic and fulvic acids (Kalbitz et al., 2003a; Wickland et al., 2007). Downward cycling of DOC through mineral soils leads to decreased DOC concentrations and aromaticity as well as increased contribution of microbial metabolites through selective adsorption, microbial processing and desorption (Kaiser and Kalbitz, 2012; Kothawala et al., 2012a). Hydrological connectivity of terrestrial sources determines magnitude, timing and composition of DOC reaching downstream aquatic ecosystems (Ågren et al., 2008; Olefeldt et al., 2013a). Peatlands are generally important catchment sources of DOC both due to the strong source capacity associated with thick organic soils and due to the lack of mineral soils that could impede and reduce export (Mattson et al., 2005; Creed et al., 2008).

Both microbial and UV-mediated rates of mineralization are linked to DOC composition (Kalbitz et al., 2003a; Obernosterer and Benner, 2004). Aromatic DOC is poorly available for microbes, but is readily mineralized or transformed into bioavailable compounds by UV light (Bertilsson and Tranvik, 2000). UV light also enhances rates of sedimentation through flocculation of aromatic DOC (von Wachenfeldt et al., 2008). In the absence of attenuation from aromatic DOC, damaging UV light slows down microbial activity (Tranvik and Bertilsson, 2001; Olefeldt et al., 2013b). Both microbial and UV-mediated removal of DOC alters the composition of the remaining pool, although often along diverging trajectories as a result of selective removal or transformation (Moran et al., 2000; Kalbitz et al., 2003b; Benner and Kaiser, 2011).

Wildfire annually burns $\sim 0.5-1 \%$ of the circumboreal forest, and burn area is projected to double by the end of this century as a result of climate change (Flannigan et al., 2009). Wildfire alters the quality of soil organic matter in shallow soil layers both through the loss of polysaccharide aliphatic $\mathrm{C}$ associated with fresh litter and through the enrichment and formation of condensed aromatic carbon compounds (e.g. in char) associated with incomplete combustion (Neff et al., 2005; Certini, 2005). Olefeldt et al. (2013b) showed that wildfire had corresponding effects on soil DOC composi- tion leached from surface soils in both boreal peatlands and forests, causing increased aromaticity. Highly aromatic DOC derived from soil char layers has been shown to be available for downstream transport, as it has been detected in in rivers, lakes and in the ocean (Hockaday et al., 2007). Charderived DOC has very low biodegradability but is rapidly mineralized or transformed into biodegradable compounds through UV processes (Stubbins et al., 2012; Olefeldt et al., 2013b), and therefore has the potential to alter aquatic C cycling if its export is significantly altered following wildfire. Few studies have, however, assessed implications for aquatic $\mathrm{C}$ cycling during the first years following wildfire (c.f. Marchand et al., 2009), and studies of catchment DOC exports and lake DOC concentrations have yielded variable shortterm responses to fire in different regions (Schindler et al., 1996; Carignan et al., 2000; McEachern et al., 2000; Allen et al., 2003; Betts and Jones, 2009; Marchand et al., 2009). Given the likelihood of increased fire frequencies and severities in boreal regions, particularly continental regions such as western Canada (Flannigan et al., 2009), understanding downstream implications of wildfire on lake $\mathrm{C}$ cycling and degradation of terrestrial DOC is important.

The purpose of this study was to evaluate the potential for recent wildfire to alter the linkages between terrestrial and aquatic $\mathrm{C}$ cycling in a boreal setting. We assessed whether wildfire altered the DOC composition of terrestrial sources, and we sampled lakes located both within and outside the recent fire perimeter in order to detect an influence of wildfire on DOC composition and lability. Several different approaches were used to assess within-lake degradation of terrestrial DOC, including incubations under both dark and UV conditions, and the implementation of a hydrological mixing model. We used absorbance and fluorescence properties of DOC to yield information on aromaticity (Weishaar et al., 2003) and relative measures of humic/fulvic acids and amino acid abundances (Fellman et al., 2010). We used this information to assess the mixing of different terrestrial DOC sources in lakes as well as to infer within-lake changes to DOC compositions as a result of selective biodegradation or UV-mediated degradation. This study stresses the importance of regional and local characteristics, including climate and surface geology, for understanding the relative contribution of various terrestrial DOC sources to aquatic ecosystems, dominant processes for aquatic DOC degradation and impacts of wildfire.

\section{Study area}

The study area is located in the Boreal Plains ecozone in north-central Alberta, within the Utikuma Region Study Area (URSA) (Fig. 1) (Devito et al., 2005; EcoRegions Working Group, 1989). The shale bedrock of the region is overlain by glacial deposits between 20 and $240 \mathrm{~m}$ thick (Vogwill, 1978). The surface geology is dominated by 


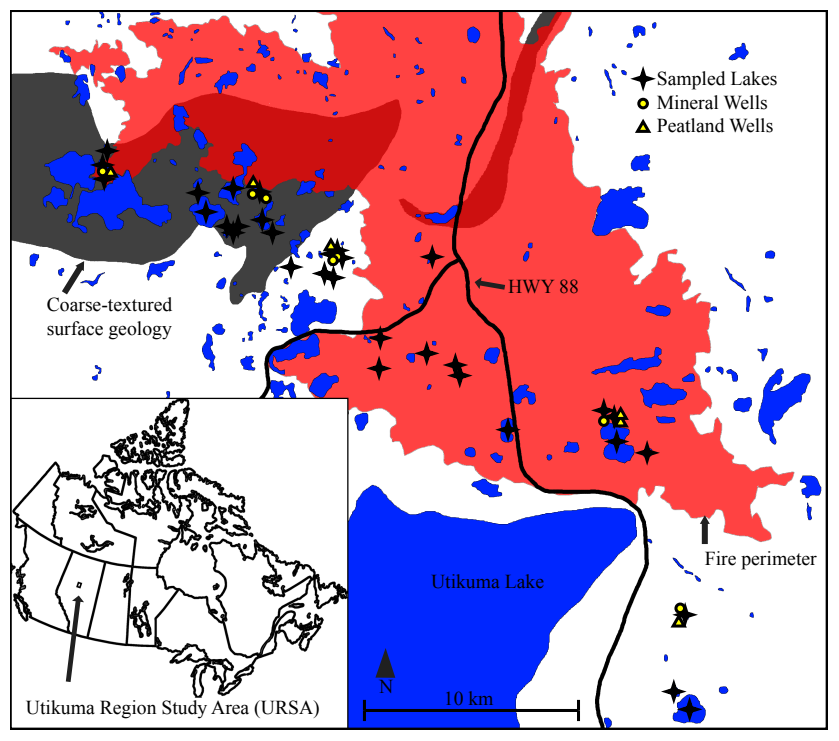

Fig. 1. Map of Utikuma Region Study Area (URSA) in north-central Alberta, Canada. Fire polygon retrieved from Canadian Forest Service (2011). North-eastern corner of Utikuma Lake is located at $55.92^{\circ} \mathrm{N}$ and $115.18^{\circ} \mathrm{W}$.

coarse-textured glacio-fluvial sand deposits in the north-west part of the study area, and by fine-textured settings with glacio-lacustrine and moraine deposits of clay and silt in the south-eastern parts (Fenton et al., 2003; Devito et al., 2005). The landscape in the region is characterized by low relief and a land cover of peatlands dominated by black spruce (Picea mariana) and uplands dominated by trembling aspen (Populus tremuloides), white spruce (Picea glauca) or pine (Pinus banksiana) depending on glacial landforms and local drainage. The region has a sub-humid climate, with average annual temperature of $1.7^{\circ} \mathrm{C}$ and monthly temperature range of -14.6 to $15.8^{\circ} \mathrm{C}$ (EcoRegions Working Group, 1989). The mean annual precipitation is slightly lower than potential evapotranspiration, 481 and $518 \mathrm{~mm}$, respectively (Marshall et al., 1999).

The region has numerous shallow $(\sim 0.5-5 \mathrm{~m})$ lakes of variable size that cover $5-10 \%$ of the landscape area. The lakes are naturally meso- to eutrophic, and occasionally experience algal blooms (Bayley et al., 2007). Mineral soil groundwater inputs to lakes are quantitatively more important for lakes in coarse-textured settings due to high hydrological conductivity in quartz sand deposits, but have low ion and nutrient concentrations for the same reason (Smerdon et al., 2008). In fine-textured settings water movement is restricted to near-surface flow paths, and mineral soil groundwater inputs are small. Near-surface flow paths are dominated by water movement through organic soils in peatlands, and peatlands adjacent to lakes represent important sources of water to the lakes, although they can also act as water sinks during dry years (Ferone and Devito, 2004). In contrast, forested upland areas seldom generate hillslope runoff since individual precipitation events rarely exceed soil storage capacity (Redding and Devito, 2008). Rather, the water table often slopes against topography, causing water to move from lake into hillslopes to recharge groundwater or be transpired. Inter-annual variability in precipitation causes the lakes to go through multi-year oscillations of drying or wetting that can reduce or increase lake water volumes significantly (Sass and Creed, 2008). Low water levels following dry periods were recorded from 1999 to 2002 and from 2009 to 2010. Water levels rose in early 2011, followed by a stable period that extended through to our sampling in the summer of 2012.

The study area was partially affected by the Utikuma Complex wildfire that broke out on 15 May 2011 and eventually burned an area of $880 \mathrm{~km}^{2}$, including the surroundings of many lakes within URSA (Fig. 1). The mean fire return interval of the Boreal Plains in Canada is $\sim 150 \mathrm{yr}$ (Flannigan et al., 2009), and the previous times when parts of the study area were affected by smaller fires were in $1952\left(96 \mathrm{~km}^{2}\right)$ and $1956\left(57 \mathrm{~km}^{2}\right.$ ) (Alberta Sustainable Resource Development, 2013).

\section{Methods and materials}

\subsection{Peatland pore-water profiles}

Peatlands were assumed to be the primary sources of DOC to the lakes, and in order to assess whether wildfire influenced peatland pore-water DOC concentrations or composition, we established depth profiles for soil pore-water sampling using rhizon pore-water samplers (Rhizosphere research products) in one peatland that burned in the previous year and in one nearby unburned peatland. Both peatlands were typical bogs for the region, with peat depths $>100 \mathrm{~cm}$, open canopies of black spruce and a surface layer with Sphagnum mosses and Bog Labrador Tea (Rhododendron groenlandicum). Wildfire caused preferential burning of Sphagnum moss in hollows with an average depth of burn of $\sim 0.1 \mathrm{~m}$ and left a $\sim 5 \mathrm{~mm}$ char layer, while wildfire singed the Sphagnum moss in hummocks but left it largely uncombusted. In each peatland, three profiles were located in hummocks and three in hollows, consisting each of rhizons inserted 5,15 and $30 \mathrm{~cm}$ below the peat surface. Rhizons consist of a microporous tube $(\varnothing=5 \mathrm{~mm}$, length $=100 \mathrm{~mm}$, pore width $=0.1 \mu \mathrm{m})$ that is connected to PVC tubing that ends above the surface with a male Luer lock that can be attached to a syringe. Rhizons are capable of collecting pore-water samples both above and below the water table. Next to each profile we inserted stilling wells where the position of the water table was measured. Five sampling occasions were performed between late May and August. Sampling was done by attaching $60 \mathrm{~mL}$ syringes to each rhizon, applying vacuum and allowing $10 \mathrm{~h}$ to collect pore water. Occasionally the rhizons were unable to collect pore-water samples, yielding 57 and 69 samples from the burned and unburned peatlands, respectively, out of 
90 possible samples at each site. Pore-water samples were transferred to $25 \mathrm{~mL}$ acid washed and pre-rinsed scintillation vials and kept cool until analysed for DOC concentration and absorbance within two weeks of collection (see below).

\subsection{Lake and well water sampling}

A synoptic sampling of lakes and wells was conducted over a 3-day period in late July 2012, i.e. 14 months after the fire. A total of 32 lakes were sampled, using a $3 \mathrm{~m}$ rod from the shore or, if needed, from the edge of the emergent vegetation of the lakes to ensure a representative lake sample taken from $\sim 30 \mathrm{~cm}$ below the water surface. Half of the lakes were located within and half were located outside the perimeter of the recent fire, and of the sampled lakes, 21 were located in fine-textured settings and 11 in coarse-textured settings (Fig. 1). Median lake size was 9 ha, and lake size ranged from 0.5 to 300 ha in both the fine- and coarse-textured settings (Table 1). Lake depths were greater in the coarsetextured settings ( $2.6 \pm 1.3 \mathrm{~m}$, average \pm 1 standard deviation used throughout manuscript) than in fine-textured $(1.6 \pm 0.6)$ ( $t$ test, $p=0.04$ ) (unpublished data on lake depth, K. Devito). Lake locations and limnological characteristics for all lakes are found in the supplementary data. Seven wells that extend 4 to $16 \mathrm{~m}$ in depth and only receive mineral soil groundwater were sampled, of which four were located in burned areas (Fig. 1). Seven wells in peatlands $(\sim 1 \mathrm{~m}$ deep, with no mineral soil contact) were also sampled, four of which were located in burned peatlands. All wells had been previously developed and were flushed prior to our sampling. In addition, we sampled surface water from small peatland pools $(<50 \mathrm{~cm}$ diameter) nearby each peatland well. Peatland well and surface water were indistinct from each other in all regards and are henceforth all referred to as peatland well samples.

Two samples were collected at each lake and well. The first sample was filtered directly in the field through $0.45 \mu \mathrm{m}$ glass fibre filters (Machery Nagel) into $1 \mathrm{~L}$ acid-washed glass bottles. The second sample was also filtered in the field, but stored in $60 \mathrm{~mL}$ glass bottles and acidified in the field by adding $100 \mu \mathrm{L} 2 \mathrm{~N}$ hydrochloric acid. The acidified sample was taken to test whether there were any DOC losses in the un-acidified sample prior to the start of the incubation experiments (see below). Both samples were kept on ice in the field, and subsequently stored cool $\left(8^{\circ} \mathrm{C}\right)$ until analysis and start of the incubations.

A synoptic lake sampling survey was also carried out in July 2003, and included 23 of the 32 lakes that were sampled in 2012. Of the lakes sampled twice (2003 and 2012), 13 of 23 were located within the recent fire perimeter and 10 outside. In 2003 the region was in a stable hydrological phase following a post-drought recovery of lake levels, similar to conditions in 2012 (K. Devito, unpublished data).

\subsection{Sample analysis}

DOC concentrations of samples collected from rhizons, lakes and wells were measured 10-14 days after sampling on a Shimadzu TOC-V. Four-point calibration curves over the range $1-100 \mathrm{mg} \mathrm{L}^{-1}$ were established for DOC using standards and Milli-Q water, and each run included one DOC standard (100 $\left.\mathrm{m} \mathrm{C} \mathrm{L}^{-1}\right)$ along with at least four Milli-Q water samples to ensure that no analytical drift occurred. Aliquots of $25 \mathrm{~mL}$ were taken from each sample and were acidified by $100 \mu \mathrm{L} 2 \mathrm{~N}$ hydrochloric acid prior to analysis unless the sample had already been acidified in the field. Samples were sparged for $2 \mathrm{~min}$ to remove dissolved inorganic carbon (DIC). Four injections of each sample were used to calculate average concentrations, yielding an average standard error of $0.2 \mathrm{mg} \mathrm{C} \mathrm{L}^{-1}$.

Electrical conductivity $(\mathrm{Ec})$ of water samples can be assumed to act conservatively when mixed, and was used to assess relative importance of different water sources to lakes (see below). Isotopes of oxygen and hydrogen $\left(\delta^{18} \mathrm{O}\right.$ and $\delta \mathrm{D}$, respectively) can also be used to assess water sources, but is further sensitive to fractionation through evaporation. $\mathrm{Ec}, \mathrm{pH}, \delta^{18} \mathrm{O}$ and $\delta \mathrm{D}$ were measured on all well and lake samples. Surface and well water Ec and temperatures were measured in the field with a calibrated temperature/level/conductivity meter (Solinst, Canada). pH was determined from samples analysed in the Biogeochemical Analytical Service Laboratory, University of Alberta, within $48 \mathrm{~h}$ of sampling. $\delta^{18} \mathrm{O}$ and $\delta \mathrm{D}$ were determined by $\mathrm{H}_{2} \mathrm{O}_{\text {(liquid) }}{ }^{-}$ $\mathrm{H}_{2} \mathrm{O}_{\text {(vapour) }}$ equilibration laser spectroscopy (Wassenaar et al., 2008) using a Los Gatos liquid water isotope analyser at the Biogeochemical Analytical Service Laboratory, University of Alberta. Results were expressed as per mil difference $(\%)$, relative to Vienna Standard Mean Oceanic Water.

\subsection{Incubation experiments}

We conducted DOC incubations under dark and UV conditions of lake and well samples in order to test for differences in microbial and UV-mediated DOC lability between different terrestrial DOC sources, between lakes in different settings and to assess any influence of wildfire. Lake and well samples that had not been acidified in the field were prepared for incubations. Samples were diluted with $0.001 \mathrm{~N} \mathrm{NaHCO}_{3}$ to DOC concentrations of $19.7 \pm 1.1 \mathrm{mg} \mathrm{C} \mathrm{L}^{-1}$ prior to incubation start. Since this study is interested in the lability of terrestrial DOC within lakes, we used the $\mathrm{NaHCO}_{3}$ to homogenize $\mathrm{pH}$ among samples, particularly to increase the $\mathrm{pH}$ of peatland well samples to approach $\mathrm{pH}$ in the lakes (average $\mathrm{pH}$ before and after dilution for peatland well samples: $4.32 \pm 0.8$ and $7.04 \pm 0.21$, respectively). Standardized DOC concentrations at $20 \mathrm{~g} \mathrm{C} \mathrm{L}^{-1}$ is in the range observed among lakes, and was also chosen to avoid excess microbial growth and associated anoxia during the incubations. Three lake and one mineral soil well sample had initial DOC 
subsequently replaced by pure $\mathrm{N}_{2}$. Analyses of headspace samples were done on an infrared gas analyser (PP Systems, EGM-1), where analytical drift was checked by sampling a $1000 \mathrm{ppm} \mathrm{CO}_{2}$ standard gas regularly. Headspace $\mathrm{CO}_{2}$ concentration, water temperature and sample $\mathrm{pH}$ were used to calculate concentrations of DIC in the water sample (Plummer and Busenberg, 1982). Initial $\mathrm{pH}$ levels of the incubation samples were all between 7.01 and 8.64 , following the dilution using $\mathrm{NaHCO}_{3}$ (see above), which is in the range of observed $\mathrm{pH}$ in the lakes. Sample $\mathrm{pH}$ could only be measured at the start and at the end of the incubation as the jars were sealed; the difference between the start and end of the incubation was $+0.1 \pm 0.15 \mathrm{pH}$ units, and we assumed linear change in $\mathrm{pH}$ during the incubations for headspace samplings at day 1,3 and 6. Changes in headspace $\mathrm{CO}_{2}$ concentration and DIC concentration were summed for estimates of $\mathrm{CO}_{2}$ production rates during the incubations, with changes in DIC concentration always representing $<15 \%$ of the $\mathrm{CO}_{2}$ production at the end of the incubation. Assuming that DOC is a mixture of components with different degradation rates, we fitted a double exponential model to the $\mathrm{CO}_{2}$ time series, which yielded estimates of the contribution of a labile and a stabile fraction to the total DOC pool, along with degradation half-lives of each fraction (Kalbitz et al., 2003a).

\subsection{Absorbance, fluorescence and PARAFAC analysis}

Absorbance and fluorescence of DOC samples yield information on DOC composition, which was used to characterize terrestrial DOC sources to lakes, to observe changes in DOC composition during dark and incubations and to infer dominant processes responsible for within-lake losses of terrestrial DOC. UV-Vis absorbance from 200 to $600 \mathrm{~nm}(1 \mathrm{~nm}$ steps) was measured on all samples on a Varian Cary 100 in a $1 \mathrm{~cm}$ quartz cuvette, with Milli-Q water used as blank. Absorbance at $254 \mathrm{~nm}\left(A_{254}\right.$ unit: $\left.\mathrm{cm}^{-1}\right)$ divided by the sample DOC concentration and multiplied by 100 yields specific UV absorbance (SUVA, unit: $\mathrm{L} \mathrm{mg} \mathrm{C}^{-1} \mathrm{~m}^{-1}$ ), which has a robust positive relationship with DOC aromaticity (Weishaar et al., 2003).

Fluorescence was measured on a Varian Cary Eclipse, and all data were multiplied by the instrument specific excitation and emission correction factors as well as corrected for primary and secondary inner filter effects using corresponding absorbance spectra (Ohno, 2002). Analytical drift of the instrument was checked daily by locating and calculating the area of the Raman peak at $350 \mathrm{~nm}$ excitation with $0.25 \mathrm{~nm}$ steps. Raman peak location was found at $396.7 \pm 0.5 \mathrm{~nm}$, and the standard deviation for peak area was $<5 \%$ of the average area - indicating that there was no significant drift during the experiment. Daily tests of cuvette contamination and blank recordings were also made. Samples were, if needed, diluted with Milli-Q water so that $A_{254}$ was $0.2 \pm 0.005 \mathrm{~cm}^{-1}$ prior to fluorescence analysis.

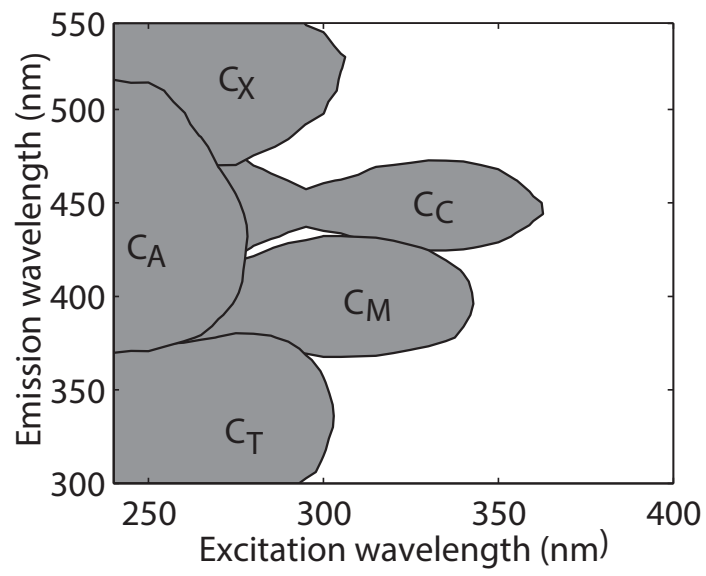

Fig. 2. Outline of peak locations for all five DOC fluorescence PARAFAC components. Outlines were drawn at equal excitation/emission loadings among components.

Fluorescence excitation/emission matrices (EEMs) were collected from aliquots drawn at the start and end of incubations. In the EEMs, fluorescence was collected over an excitation range from 240 to $400 \mathrm{~nm}$ ( $5 \mathrm{~nm}$ increments) and an emission range from 300 to $550 \mathrm{~nm}$ ( $2 \mathrm{~nm}$ increments), using $0.25 \mathrm{~s}$ averaging times. Fluorescence intensities were normalized to both the area of the Raman peak and to the sample DOC concentration, and thus EEM fluorescence intensities were expressed in Raman Units (R.U.) per unit DOC concentration (i.e. R.U. $\mathrm{mg} \mathrm{C}^{-1} \mathrm{~L}$ ). As such, fluorescence is expressed in a way analogous to SUVA (i.e. fluorescence or absorbance per unit DOC). The collected 171 EEMs were used in a parallel factor (PARAFAC) analysis using DOMFluor Toolbox v.1.7, whereby fluorescing components are identified and their contribution to individual EEMs is quantified (Stedmon and Bro, 2008). The PARAFAC analysis of this study validated a five-component model using a split-half approach. Residuals between measured and modelled EEMs by the PARAFAC analysis showed no discernible patterns and had intensities $\sim 2$ orders of magnitude lower than in the measured EEMs, indicating that no significant fluorophores were unaccounted for by the model. The components had smooth single peaks in their emission loadings and single or double peaks in their excitation loadings (Fig. 2 and Table 2). Peak regions of each component corresponded well with previously identified fluorophores, and components $C_{\mathrm{C}}$ and $C_{X}$ were accordingly interpreted as being associated with HMW fulvic/humic acids; $C_{\mathrm{A}}$ with HMW fulvic acids; $C_{\mathrm{M}}$ with LMW fulvic/humic acids; and $C_{\mathrm{T}}$ with the amino acids tryptophan and tyrosine that can be free or bound in proteins (Coble, 1996; Fellman et al., 2010). 
Table 2. Description of DOC fluorescence components identified by PARAFAC analysis.

\begin{tabular}{lrrlll}
\hline Component & $\begin{array}{r}\mathrm{Ex}^{1} \\
(\mathrm{~nm})\end{array}$ & $\begin{array}{r}\text { Em } \\
(\mathrm{nm})\end{array}$ & Description & $\begin{array}{l}\text { Primary } \\
\text { peaks }^{2}\end{array}$ & $\begin{array}{l}\text { Probable } \\
\text { sources }^{3}\end{array}$ \\
\hline$C_{\mathrm{C}}$ & $<240,330$ & 444 & UV-A/C fulvic/humic, HMW & $\mathrm{A}+\mathrm{C}$ & $\mathrm{T}$ \\
$C_{\mathrm{A}}$ & $<240$ & 432 & UV-A fulvic, HMW & $\mathrm{A}$ & $\mathrm{T}$ \\
$C_{\mathrm{X}}$ & 255,380 & 522 & UV-A/C fulvic/humic HMW & - & $\mathrm{T}$ \\
$C_{\mathrm{M}}$ & $<240,305$ & 396 & UV-A/C fulvic/humic LMW & $\mathrm{A}+\mathrm{M}$ & $\mathrm{T}, \mathrm{A}, \mathrm{M}$ \\
$C_{\mathrm{T}}$ & $<240,275$ & 336 & $\begin{array}{l}\text { Amino acids; tryptophan and } \\
\text { tyrosine, free or bound in protein }\end{array}$ & $\mathrm{T}+\mathrm{B}$ & $\mathrm{T}, \mathrm{A}, \mathrm{M}$ \\
& & & & \\
\hline
\end{tabular}

\footnotetext{
1 Wavelengths in italics indicate secondary maxima.

2 See Coble (1996) and Fellman et al. (2010) for further details on primary fluorescing peaks.

$3 \mathrm{~T}$ - terrestrial, plant or soil organic matter; $\mathrm{A}$ - autochthonous production; $\mathrm{M}$ - microbial processing.
}

\subsection{Using a hydrological mixing model to assess DOC sources to lakes and within-lake DOC losses}

We used a two-step hydrological mixing model to assess (step one) the fractional contribution of water and DOC to lakes from either mineral soil or peatland groundwater sources and (step two) to assess losses of terrestrial DOC and $A_{254}$ within lakes. The first step assumes that Ec of the water sources mixes conservatively in lakes, while the second step assumes that both DOC and $A_{254}$ act non-conservatively as a result of DOC mineralization and sedimentation in lakes. The model also takes into account the effects of lake concentration or dilution due to the water balance of the lakes, and the contribution of algal DOC to the lake DOC pool. The goal of the mixing model is to assess whether source dynamics or within-lake losses of terrestrial DOC can be found to be sensitive to the recent wildfire, or to the hydrogeological setting of the lakes. By assessing both within-lake losses of DOC and $A_{254}$ we can also draw conclusions on what type of DOC compounds that have been preferentially lost in lakes, which we can compare to observed losses during dark and UV incubations to infer dominant processes of DOC removal in the lakes.

In the first step of the mixing model, we solved for the fractional contribution from mineral soil $\left(f_{\mathrm{M}}\right)$ and peatland groundwater $\left(f_{\mathrm{P}}\right)$ to each lake, using Ec as a conservative tracer:

$\mathrm{Ec}_{\text {Lake }}=\left(f_{\mathrm{M}} \times \mathrm{Ec}_{\mathrm{M}}+f_{\mathrm{P}} \times \mathrm{Ec}_{\mathrm{P}}\right) /(1-C)$,

where $f_{\mathrm{M}}$ and $f_{\mathrm{P}}$ sum to $1, \mathrm{Ec}_{\text {Lake }}$ is the measured lake $\mathrm{Ec}$, and $\mathrm{Ec}_{\mathrm{M}}$ and $\mathrm{Ec}_{\mathrm{P}}$ are representative estimates of mineral soil and peatland groundwater $E c$, respectively. $F o r ~ E c_{P}$ we used the average Ec measured in peatland well water samples, $55 \mu \mathrm{S} \mathrm{cm}^{-1}$ (see results). Ec of mineral soil groundwater sources are known to vary between wells in fine- (clay) and coarse- (quartz sand) textured substrates in the region, and values used as $\mathrm{Ec}_{\mathrm{M}}$ for lakes in fine- and coarse-textured sections were 1000 and $200 \mu \mathrm{S} \mathrm{cm}^{-1}$, respectively, based on previous measurements of a larger set of wells in the region (Ferone, 2001; Gibbons, 2003). The factor $C$ represents the fraction of the lake water volume that estimated potential evaporation was greater than direct precipitation to the lakes over the year preceding the sampling. We estimated $C$ for each lake:

$C=\left(\mathrm{Et}_{0}-P\right) / D$,

where $\mathrm{Et}_{0}$ is the cumulative potential evapotranspiration over the preceding year $(0.63 \mathrm{~m})$ as estimated using the Hargreaves model (Hargreaves and Samani, 1982), which takes into account daily air temperature and incoming solar radiation that we obtained from the nearest climate station in High Prairie, located $80 \mathrm{~km}$ from the study area (Alberta Agriculture and Rural Development, 2013); $P$ is the average cumulative precipitation for the same period $(0.52 \mathrm{~m})$ from three precipitation gauges located within the study area (K. Devito, unpublished data); and $D$ is lake depth (varying between 0.5 and $5 \mathrm{~m}$ ). Hence, assuming average lake water residence times of $1 \mathrm{yr}$, we estimate that lake Ec has been concentrated by $6.3 \pm 3.0 \%$ due to lake evaporation being greater than precipitation, with the variation dependent on lake depth.

In the second step of the mixing model, we first estimate what lake DOC concentrations and $A_{254}$ would be if there were no within-lake losses of terrestrial DOC resulting from mineralization or sedimentation and if there were no contribution of algal DOC to the lake DOC pool (i.e. as if DOC and $A_{254}$ mixed conservatively):

$\mathrm{DOC}_{\mathrm{Est}}=f_{\mathrm{M}} \times \mathrm{DOC}_{\mathrm{M}}+f_{\mathrm{P}} \times \mathrm{DOC}_{\mathrm{P}}$,

where $\mathrm{DOC}_{\mathrm{Est}}$ is the estimated lake DOC concentration in the absence of within-lake losses and any contribution from algal DOC, and where $\mathrm{DOC}_{\mathrm{M}}$ and $\mathrm{DOC}_{\mathrm{P}}$ are mineral soil and peatland groundwater DOC concentrations at 19 and $82 \mathrm{mg} \mathrm{CL}^{-1}$, respectively (see results). $A_{254 \text { Est }}$ was estimated analogously, where $A_{254 \mathrm{M}}$ and $A_{254 \mathrm{P}}$ were 0.15 and $3.02 \mathrm{~cm}^{-1}$, respectively. As DOC and $A_{254}$ are assumed to mix non-conservatively in lakes due to mineralization and sedimentation, the fraction of within-lake losses of terrestrial DOC $\left(\mathrm{DOC}_{\Delta}\right)$ and $A_{254}\left(A_{254 \Delta}\right)$ can be estimated as

$\mathrm{DOC}_{\Delta}=\left(\mathrm{DOC}_{\mathrm{Est}}-\left[\mathrm{DOC}_{\mathrm{L}} \times\{1-A\} \times\{1-C\}\right]\right) / \mathrm{DOC}_{\mathrm{Est}}$, 
where $\mathrm{DOC}_{\mathrm{L}}$ is the observed lake DOC concentration and $A$ is an estimated fraction of the lake DOC pool that is assumed to be of algal rather than terrestrial origin. By using a reported relationship (Bade et al., 2007) for algal contribution to boreal lake DOC as a function of lake absorbance at $440 \mathrm{~nm}$ (data from this study) and chlorophyll $a$ concentrations (data from Sass et al., 2008), we estimated that algal DOC represents on average $15 \%$ of the DOC in the studied lakes (i.e. $A=0.15$ ). $A_{254 \Delta}$ was estimated analogously, although since algal DOC has negligible absorbance at $254 \mathrm{~nm}$, we assumed $A=0$.

In order to assess the uncertainty of the mixing model results, we implemented a Monte Carlo approach where the mixing model was solved 5000 times for each lake and where each run used values for the included constants of the model based on normal distribution probability functions. We used the measured averages \pm 2 standard deviations of mineral soil and peatland well samples (see Results) to estimate the $95 \%$ confidence intervals for $\mathrm{DOC}_{\mathrm{M}}$, $\operatorname{DOC}_{\mathrm{P}}\left(19 \pm 15\right.$ and $82 \pm 20 \mathrm{mg} \mathrm{CL}^{-1}$, respectively), $A_{254 \mathrm{M}}$, $A_{254 \mathrm{P}}\left(0.15 \pm 0.05\right.$ and $3.03 \pm 0.25 \mathrm{~cm}^{-1}$, respectively) and $\mathrm{Ec}_{\mathrm{P}}\left(55 \pm 24 \mu \mathrm{S} \mathrm{cm}^{-1}\right)$. Measured mineral soil groundwater had highly variable $\mathrm{Ec}\left(1155 \pm 833 \mu \mathrm{S} \mathrm{cm}^{-1}\right)$, but a wider set of mineral soil wells that have been regularly sampled within URSA have shown that mineral soil wells in the fine-textured settings have Ec that is significantly higher than for wells in coarse-textured regions (Ferone, 2001; Gibbons, 2003). Based on this, we used central values and $95 \%$ confidence intervals of $1000 \pm 500$ and $200 \pm 50 \mu \mathrm{S} \mathrm{cm}^{-1}$ as $\mathrm{Ec}_{\mathrm{M}}$ for lakes in fine- and coarse-grained settings, respectively. The used confidence intervals for $\mathrm{Et}_{0}$ and $P$ were $0.63 \pm 0.25 \mathrm{~m}$ and $0.52 \pm 0.15$, respectively. We assumed a $0.15 \pm 0.15$ confidence interval for $A$ based on the range of observed Chl $a$ and $A_{440}$ among the studies lakes (Sass et al., 2008). The Monte Carlo analysis produced central estimates and associated $95 \%$ confidence intervals of $f_{\mathrm{M}}, f_{\mathrm{P}}, \mathrm{DOC}_{\mathrm{Est}}, \mathrm{DOC}_{\Delta}$, $A_{254 \text { Est }}$ and $A_{254 \Delta}$ for each lake.

\subsection{Statistical analysis}

All statistical analysis was performed in MatLab R2011b. Individual and multiple regressions of lake DOC composition (SUVA along with the five PARAFAC components) as dependent variables and $f_{\mathrm{P}}$ and $\delta^{18} \mathrm{O}$ as independent variables were run, reporting $F, R^{2}$, adjusted $R^{2}$ and $p$ values. Both the $p$ value for the overall model and for the individual independent variables are reported for multiple regressions. Analysis of covariance (ANCOVA) was used to assess whether lake characteristics (burned/unburned areas or fine-/coarsetextured settings) influenced the slope of the relationship between lake SUVA and Ec or $\delta^{18} \mathrm{O}$. ANCOVA was also used to assess if the relationships between lake DOC concentrations in 2003 and 2012 were affected by whether the lake was within or outside the recent fire perimeter. The curve fitting toolbox was used to fit least-squares regressions (Levenberg-
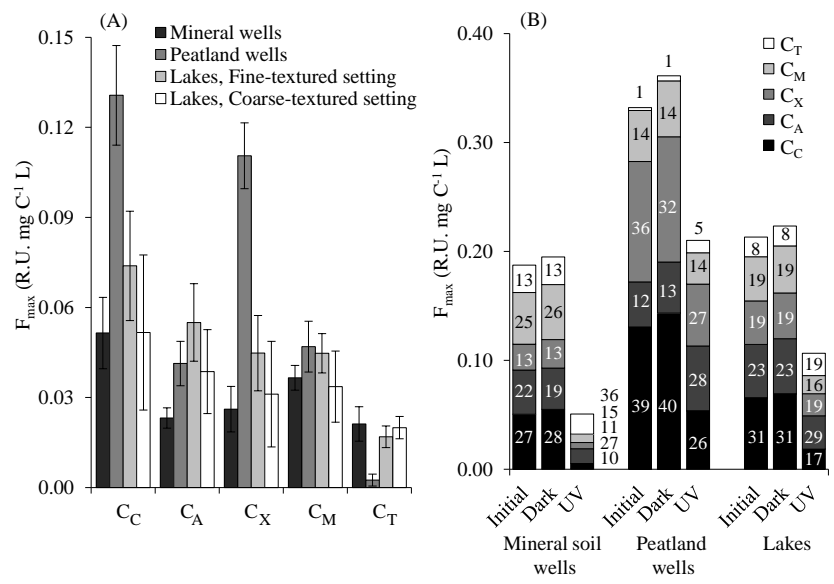

Fig. 3. Maximum fluorescing intensities $\left(F_{\max }\right)$ of the five PARAFAC components for terrestrial DOC sources and lake DOC. (A) Start of incubation PARAFAC component $F_{\max }$ for lakes and wells, reporting averages \pm 1 standard deviation for 4 mineral wells, 11 peatland wells, 19 lakes in fine-textured settings and 11 lakes in coarse-textured settings. (B) Comparison of average PARAFAC profiles at the start of the incubation versus after 11-day dark and UV incubations. Numbers in or near bars indicate the percent contribution of a component to the total fluorescence of all components (i.e. they sum to 100 in each bar).

Marquandt) to $\mathrm{CO}_{2}$ production time series, and all reported regressions had $R^{2}>0.99$.

\section{Results}

\subsection{Terrestrial DOC sources}

Water samples from peatland wells had lower Ec and $\mathrm{pH}$ and higher DOC concentrations, $A_{254}$ and SUVA than mineral soil wells, while $\delta \mathrm{D}$ and $\delta^{18} \mathrm{O}$ did not differ between peatland and mineral soil wells (Table 3). Peatland wells also had higher contributions of the $C_{\mathrm{C}}$ and $C_{\mathrm{X}}$ PARAFAC components (associated with humic and fulvic acids) than mineral soil wells, while $C_{\mathrm{T}}$ (associated with amino acids) was very low in peatland wells (Fig. 3a). Components $C_{\mathrm{A}}$ and $C_{\mathrm{M}}$ did not differ between peatland and mineral soil wells. No difference in water chemistry or DOC composition could be detected between wells located within or outside the recent fire perimeter, tested both for peatland and mineral soil wells.

The rhizon depth profiles showed that burned and unburned peatlands had similar patterns of decreasing DOC concentrations above the water table but that burned peatlands had higher SUVA near or above the water table (Fig. 4). Using rhizon location in relation to the water table rather than to the peat surface led to depth profiles for DOC concentration and SUVA that were similar across hollow and hummock profiles. The water table was located on average $8.5 \pm 7.0 \mathrm{~cm}$ (all reported data represent averages \pm 1 
Table 3. Water chemistry of terrestrial DOC sources. Averages \pm 1 standard deviation.

\begin{tabular}{lcccc}
\hline & \multicolumn{2}{c}{ Mineral soil wells } & \multicolumn{2}{c}{ Peatland wells } \\
& $\begin{array}{c}\text { Burned } \\
\text { area }\end{array}$ & $\begin{array}{c}\text { Unburned } \\
\text { area }\end{array}$ & $\begin{array}{c}\text { Burned } \\
\text { area }\end{array}$ & $\begin{array}{c}\text { Unburned } \\
\text { area }\end{array}$ \\
& $n=4$ & $n=3$ & $n=9$ & $n=4$ \\
\hline $\mathrm{Ec}\left(\mu \mathrm{cm}^{-1}\right)$ & $1310 \pm 820^{*}$ & $1042 \pm 780^{*}$ & $59.4 \pm 14.5$ & $54.5 \pm 11.0$ \\
$\delta^{18} \mathrm{O}(\% \circ)$ & $-18.7 \pm 0.97$ & $-19.0 \pm 0.46$ & $-18.1 \pm 1.19$ & $-17.8 \pm 0.70$ \\
$\mathrm{pH}$ & $7.32 \pm 0.37$ & $7.46 \pm 0.24$ & $4.76 \pm 1.22$ & $4.27 \pm 0.80$ \\
$\mathrm{DOC}\left(\mathrm{mg} \mathrm{C} \mathrm{L}^{-1}\right)$ & $16.6 \pm 7.3$ & $28.3 \pm 11.4$ & $88.6 \pm 18.8$ & $71.3 \pm 4.6$ \\
$A_{254}\left(\mathrm{~cm}^{-1}\right)$ & $0.15 \pm 0.07$ & $0.19 \pm 0.08$ & $3.30 \pm 0.76$ & $2.60 \pm 0.15$ \\
SUVA $\left(\mathrm{L} \mathrm{mg} \mathrm{C}^{-1} \mathrm{~m}^{-1}\right)$ & $0.89 \pm 0.11$ & $0.69 \pm 0.11$ & $3.71 \pm 0.18$ & $3.65 \pm 0.04$ \\
\hline
\end{tabular}

* Mineral soil well Ec was influenced by soil texture (see text).
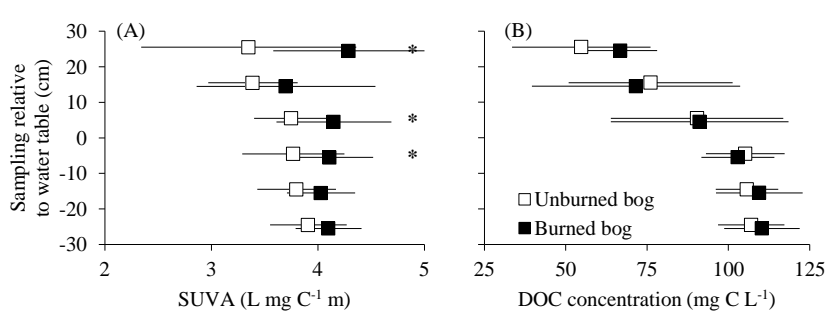

Fig. 4. Depth profiles of (A) SUVA and (B) DOC concentrations in an unburned and a burned bog. Averages \pm 1 standard deviation are shown for samples taken within each $10 \mathrm{~cm}$ depth segment. Significant differences $(t$ test, $p<0.05)$ between burned and unburned bogs are indicated $(*)$.

standard deviation) below the peat surface adjacent to rhizon profiles in hollows and $31.5 \pm 10.5 \mathrm{~cm}$ below the surface for hummock profiles, with no differences among sampling occasions or between the burned and unburned peatlands (twoway ANOVA, all $p>0.05)$.

\subsection{Lake water chemistry and DOC characteristics}

Sampled lakes exhibited a large variability in water chemistry, with averages of Ec, $133 \pm 70 \mu \mathrm{S} \mathrm{cm}^{-1}$; $\mathrm{pH}, \quad 7.99 \pm 0.95 ; \quad \mathrm{DOC}, \quad 35.7 \pm 13.3 \mathrm{mgCL}^{-1} ; \quad \delta \mathrm{D}$, $-100.8 \pm 6.7 \%$; and $\delta^{18} \mathrm{O},-9.00 \pm 1.38 \%$. Concentrations of DOC measured in 2003 were similar to DOC concentrations in 2012, suggesting no detectable influence of the 2011 fire (Fig. 5). Lakes in fine-textured settings had significantly higher DOC concentrations than lakes in coarse-textured settings (averages of 42.5 and $24.1 \mathrm{mg} \mathrm{CL}^{-1}$, respectively, Table 1 ), but lake setting did not significantly influence lake $\mathrm{Ec}, \mathrm{pH}, \delta \mathrm{D}$ or $\delta^{18} \mathrm{O}$. With regards to a mixing of terrestrial sources, lakes generally had Ec and DOC concentrations intermediate to observations in mineral soil and peatland wells, while lake $\mathrm{pH}, \delta \mathrm{D}$ and $\delta^{18} \mathrm{O}$ were higher than values observed in wells. Enriched lake $\delta \mathrm{D}$ and $\delta^{18} \mathrm{O}$ relative to water sources along with deviation from

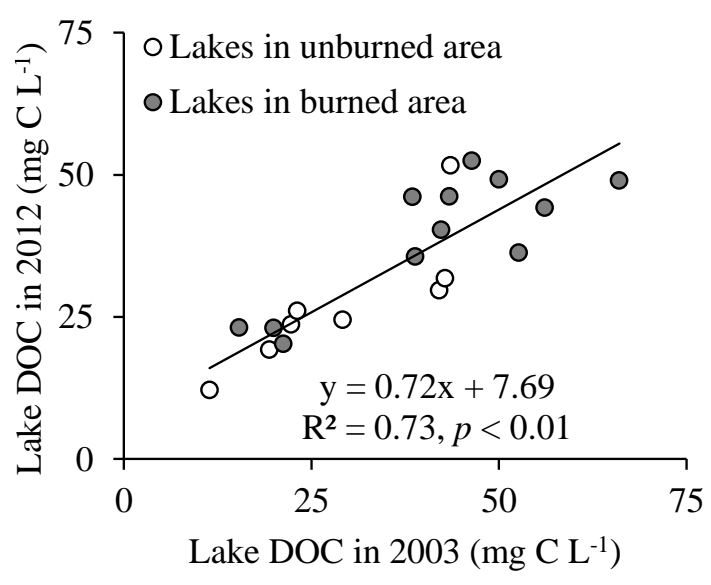

Fig. 5. Comparison of lake DOC concentrations in 2012 and 2003, where a subset of the lakes are located within a 2011 fire perimeter. Individual trend lines for lakes in burned and unburned areas were not different (ANCOVA, $F_{1,19}=0.51, p=0.52$ ), and a single trend line is shown.

the local meteoric water line suggest evaporative isotopic enrichment (Fig. 6).

Lakes also exhibited a large variability in DOC composition, with systematic differences between lakes in fineand coarse-textured settings (Table 1). Average lake SUVA among all lakes was $2.00 \pm 0.48 \mathrm{~L} \mathrm{mg} \mathrm{C}^{-1} \mathrm{~m}^{-1}$, with higher estimates for lakes in fine-textured than coarse-textured settings (averages at 2.18 and $1.56 \mathrm{~L} \mathrm{mg} \mathrm{C}^{-1} \mathrm{~m}^{-1}$, respectively; $t$ test, $p<0.001)$. Lakes in fine-textured settings also had higher $C_{\mathrm{C}}, C_{\mathrm{A}}, C_{\mathrm{X}}$ and $C_{\mathrm{M}}$ than lakes in coarse-textured settings (components associated with humic and fulvic acids), while $C_{\mathrm{T}}$ (associated with amino acids) was lower ( $t$ tests done for each component, all $p<0.02$ ) (Fig. 3a). Variation in lake SUVA was significantly related to both lake Ec and $\delta^{18} \mathrm{O}$, where lake hydrogeological setting altered the relationship between lake SUVA and Ec (Fig. 7a). Lake $f_{\mathrm{P}}$ (see below), which takes into account the difference in mineral groundwater Ec between fine- and coarse-textured settings to estimate the relative contribution of peatland water, had 


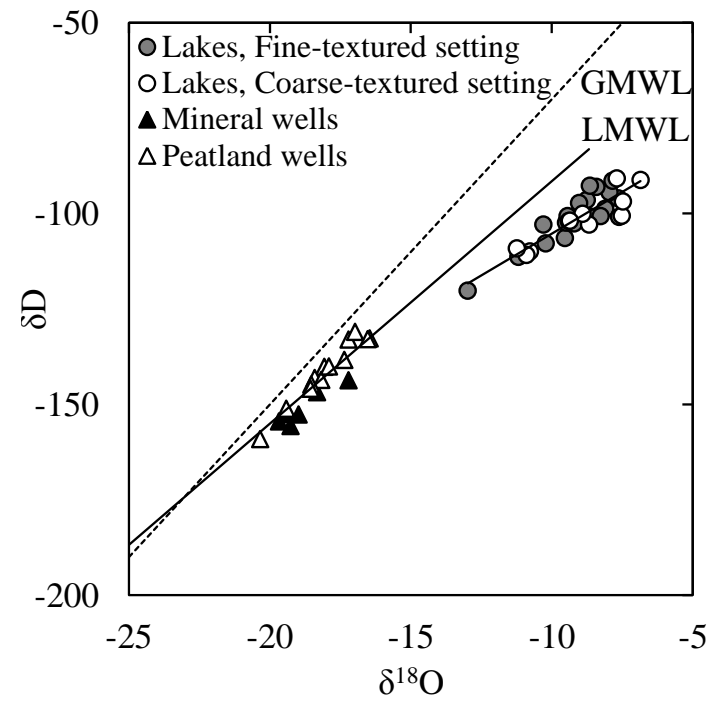

Fig. 6. Isotopic signatures of mineral soil groundwater, peatland groundwater and lake samples. Shown are also the global meteoric water line (GMWL, dashed), the local meteoric water line (LMWL) and a linear fit for all lake samples $\left(R^{2}=0.78, n=30, p<0.001\right)$.

significant relationships with all DOC composition indices (Table 4). Multiple regressions showed that lake DOC composition, particularly SUVA, $C_{\mathrm{C}}, C_{\mathrm{A}}$ and $C_{\mathrm{X}}$, were best described by models that included both $f_{\mathrm{P}}$ and $\delta^{18} \mathrm{O}$, suggesting that lake DOC composition was influenced both by the mixing of terrestrial DOC sources and water residence time as indicated by lake evaporative enrichment (see Discussion). Whether lakes were located within or outside the recent fire perimeter did not affect any of the lake DOC composition indices, neither on its own nor in combination with $f_{\mathrm{P}}$ and $\delta^{18} \mathrm{O}$ (not shown).

\subsection{Well and lake DOC incubations}

There was no difference in DOC concentration between lake and well samples that were acidified/filtered at the time of sampling versus those that had been filtered only (pairwise $t$ test, $p=0.35$ ), suggesting that there was no significant DOC degradation in the filtered samples prior to the start of the incubation experiment.

Changes in DOC concentrations during dark incubations showed that mineral well DOC was more readily lost than DOC from peatland wells $(4.8 \pm 4.2 \%$ loss versus $-0.5 \pm 2.5 \%$ loss, respectively; $t$ test, $p=0.015$ ) (Fig. 8a). Loss of DOC from lake samples was also low at $0.10 \pm 2.7 \%$, i.e. indistinguishable from 0 given the precision of the DOC concentration measurements. Neither hydrogeological setting nor fire history influenced loss of DOC during dark incubations from lake samples. There was a weak but significant negative relationship between sample SUVA and DOC loss during dark incubations across all incubations $\left(R^{2}=0.07, n=51, p=0.04\right)$. Losses of DOC

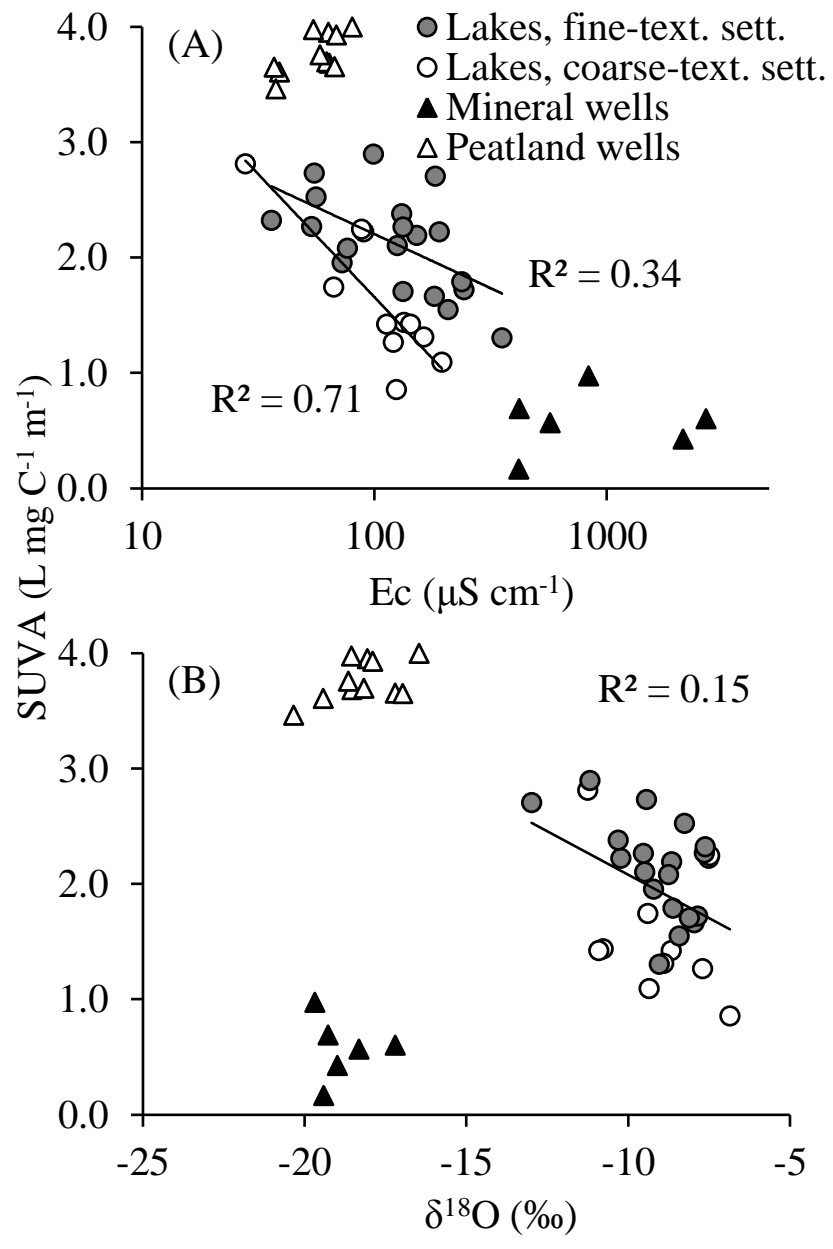

Fig. 7. Variability and relationships between water chemistry and SUVA for lakes and terrestrial sources, (A) Ec and (B) $\delta^{18} \mathrm{O}$. Only significant $(p<0.05)$ relationships are shown with trend lines. Lakes in fine- and coarse-textured settings had differing logarithmic relationships for SUVA/Ec (ANCOVA, $F_{1,26}=4.45, p=0.01$ ), while all lakes had a common linear relationship for SUVA $/ \delta^{18} \mathrm{O}$ $\left(F_{1,26}=0.42, p=0.52\right)$.

during UV incubations were greater for peatland well samples $(14.5 \pm 3.5 \%)$ than mineral well samples $(2.0 \pm 3.3 \%)$ ( $t$ test, $p<0.001$ ), and initial SUVA across all samples had a strong positive relationship with UV incubation DOC losses (Fig. 8b). However, initial sample SUVA had its strongest relationship with the difference between UV and dark incubation DOC losses (Fig. 8c). Losses of DOC during UV incubations were lower than during dark incubations for mineral soil well samples, $-2.0 \pm 2.7 \%$ (i.e. UV minus dark incubation losses), while UV incubation significantly enhanced losses for peatland well DOC, $+13.9 \pm 3.5 \%$. Neither lake setting nor fire history affected either losses during the UV incubations or the difference between UV and dark incubation DOC losses. 
Table 4. Regression analysis where lake DOC composition indices (SUVA along with the five PARAFAC components) are dependent variables, while $f_{\mathrm{P}}$ (indicating relative contribution from peatland and mineral DOC sources to lakes) and $\delta^{18} \mathrm{O}$ (indicating lake water residence time) are continuous independent variables.

\begin{tabular}{|c|c|c|c|c|c|c|}
\hline \multirow[t]{2}{*}{ Model } & \multirow[t]{2}{*}{$R^{2}$} & \multirow[t]{2}{*}{ Adj. $R^{2}$} & \multirow[t]{2}{*}{$F$} & \multicolumn{3}{|c|}{$p$} \\
\hline & & & & Overall & $f_{\mathrm{P}}$ & $\delta^{18} \mathrm{O}$ \\
\hline $\begin{array}{l}\text { SUVA }\left(\mathrm{L} \mathrm{mg} \mathrm{C}^{-1} \mathrm{~m}^{-1}\right)= \\
=0.61+1.64 \times f_{\mathrm{P}} \\
=0.77-0.13 \times \delta^{18} \mathrm{O} \\
=-0.53+1.64 \times f_{\mathrm{P}}-0.13 \times \delta^{18} \mathrm{O}\end{array}$ & $\begin{array}{l}0.56 \\
0.11 \\
0.66\end{array}$ & $\begin{array}{l}0.54 \\
0.07 \\
0.64\end{array}$ & $\begin{array}{r}34.19 \\
3.22 \\
25.67\end{array}$ & $\begin{array}{r}<0.001 \\
0.045 \\
<0.001\end{array}$ & $<0.001$ & 0.008 \\
\hline $\begin{array}{l}C_{\mathrm{C}}(\text { R.U. mg C } \\
=0.11 \\
=008+0.071 \times f_{\mathrm{P}} \\
=0.022-0.005 \times \delta^{18} \mathrm{O} \\
=-0.034+0.071 \times f_{\mathrm{P}}-0.005 \times \delta^{18} \mathrm{O}\end{array}$ & $\begin{array}{l}0.52 \\
0.07 \\
0.60\end{array}$ & $\begin{array}{l}0.50 \\
0.08 \\
0.57\end{array}$ & $\begin{array}{r}29.52 \\
2.09 \\
18.97\end{array}$ & $\begin{array}{r}<0.001 \\
0.121 \\
<0.001\end{array}$ & $<0.001$ & 0.042 \\
\hline $\begin{array}{l}C_{\mathrm{A}}(\text { R.U. mg C } \\
=0.016+0.041 \times f_{\mathrm{P}} \\
=0.002-0.005 \times \delta^{18} \mathrm{O} \\
=0.002030+0.041 \times f_{\mathrm{P}}-0.005 \times \delta^{18} \mathrm{O} \\
=-0.030\end{array}$ & $\begin{array}{l}0.37 \\
0.19 \\
0.56\end{array}$ & $\begin{array}{l}0.35 \\
0.16 \\
0.53\end{array}$ & $\begin{array}{r}16.04 \\
6.39 \\
16.71\end{array}$ & $\begin{array}{r}<0.001 \\
0.018 \\
<0.001\end{array}$ & $<0.001$ & 0.002 \\
\hline $\begin{array}{l}C_{\mathrm{X}}(\text { R.U. mg C } \\
=0.001+0.047 \times f_{\mathrm{P}} \\
=0.00-0.003 \times \delta^{18} \mathrm{O} \\
=0.00-0.024+0.047 \times f_{\mathrm{P}}-0.003 \times \delta^{18} \mathrm{O} \\
=-0.00\end{array}$ & $\begin{array}{l}0.51 \\
0.07 \\
0.58\end{array}$ & $\begin{array}{l}0.49 \\
0.05 \\
0.55\end{array}$ & $\begin{array}{r}28.01 \\
2.91 \\
18.51\end{array}$ & $\begin{array}{r}<0.001 \\
0.122 \\
<0.001\end{array}$ & $<0.001$ & 0.048 \\
\hline $\begin{array}{l}C_{\mathrm{M}}(\text { R.U. mg C } \\
=0.115)= \\
=0.015+0.032 \times f_{\mathrm{P}} \\
=0.024-0.002 \times \delta^{18} \mathrm{O} \\
=0.001+0.032 \times f_{\mathrm{P}}-0.002 \times \delta^{18} \mathrm{O}\end{array}$ & $\begin{array}{l}0.50 \\
0.05 \\
0.55\end{array}$ & $\begin{array}{l}0.48 \\
0.01 \\
0.42\end{array}$ & $\begin{array}{r}27.07 \\
1.49 \\
16.03\end{array}$ & $\begin{array}{r}<0.001 \\
0.231 \\
<0.001\end{array}$ & $<0.001$ & 0.095 \\
\hline $\begin{array}{l}C_{\mathrm{T}}\left(\text { R.U. } \mathrm{mg} \mathrm{C}^{-1} \mathrm{~L}\right)= \\
=0.025-0.008 \times f_{\mathrm{P}} \\
=0.027+0.001 \times \delta^{18} \mathrm{O} \\
=0.032-0.075 \times f_{\mathrm{P}}+0.001 \times \delta^{18} \mathrm{O}\end{array}$ & $\begin{array}{l}0.14 \\
0.10 \\
0.23\end{array}$ & $\begin{array}{l}0.11 \\
0.06 \\
0.17\end{array}$ & $\begin{array}{l}4.38 \\
2.82 \\
3.79\end{array}$ & $\begin{array}{l}0.046 \\
0.096 \\
0.036\end{array}$ & 0.046 & 0.094 \\
\hline
\end{tabular}
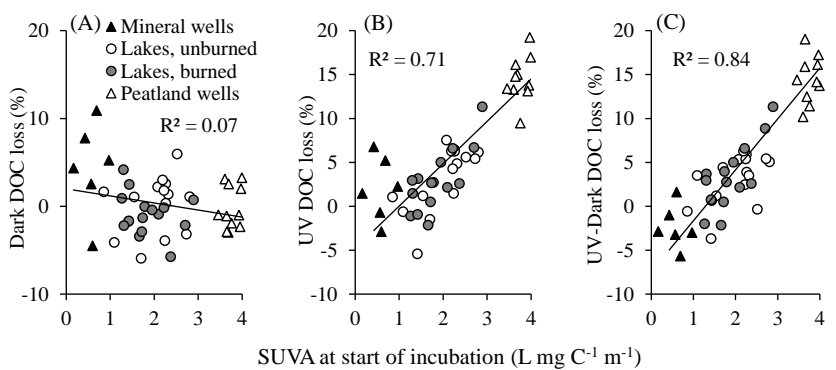

Fig. 8. Influence of SUVA on (A) dark incubations losses (B) UV incubation losses and (C) the difference between UV and dark incubation losses. Significant relationships between SUVA and DOC losses were found in all cases, but were weaker for dark DOC losses $(p=0.045)$ than for UV or UV-dark losses (both $p<0.001$ ).

Production of $\mathrm{CO}_{2}$ during incubations was correlated with measured DOC losses across all samples $\left(R^{2}=0.70\right.$, $p<0.001$ ), although $\mathrm{CO}_{2}$ production exhibited less variation, likely due to better measurement precision than for
DOC losses (Fig. 9). For mineral soil wells the production of precipitate, likely calcium carbonate, caused negative $\mathrm{CO}_{2}$ production, and their $\mathrm{CO}_{2}$ production was therefore not considered further. For peatland well samples, $\mathrm{CO}_{2}$ production was lower than DOC losses during UV incubations ( $7.2 \pm 1.2 \%$ loss versus $14.1 \pm 2.3 \%$ loss, respectively; pairwise $t$ test, $n=12, p<0.001$ ), suggesting substantial production of particulate organic carbon (Fig. 9). For lake samples during $\mathrm{UV}$ incubations, $\mathrm{DOC}$ losses and $\mathrm{CO}_{2}$ production were not significantly different $(p=0.69)$. The double exponential fit to $\mathrm{CO}_{2}$ production time series estimated that $1.2 \%$ of the DOC pool in lake and peatland well samples was labile during dark incubations and had a half-life of 3.4 days, while the stabile pool had a half-life of $>5000$ days. During UV incubations, lakes and peatland samples had labile fractions at 3.2 and $6.7 \%$, respectively, with common half-lives of 4.7 and 450 days for the labile and stabile DOC pools, respectively.

Lake and well samples exhibited decreasing SUVA during UV incubations (pairwise $t$ test, $p<0.001$ ), while SUVA 


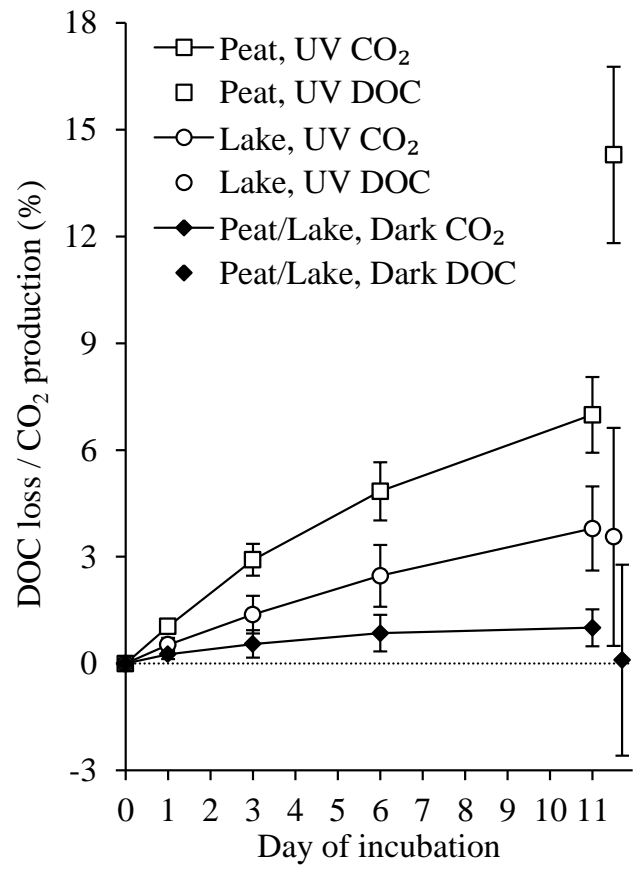

Fig. 9. Production of $\mathrm{CO}_{2}$ during dark and $\mathrm{UV}$ incubations of lake DOC samples, reported as a fraction of the initial DOC pool, compared to measurements of DOC loss, comparing initial and end of incubation DOC concentrations. Error bars indicate \pm 1 standard deviation, $n=30$. Results from mineral well incubations not included since $\mathrm{CO}_{2}$ production estimates were affected by calcium carbonate precipitation.

remained stable during dark incubations $(p=0.31)$. Decreased SUVA during UV incubations was a result of consistently more rapid $A_{254}$ loss than DOC loss (16.4 versus $5.3 \%$ losses on average, respectively, across all samples). Only minor changes were found for PARAFAC components during dark incubations, while $C_{\mathrm{C}}$ and $C_{\mathrm{X}}$ decreased and $C_{\mathrm{T}}$ increased during UV incubations (both when considered as fluorescence per units DOC, R.U. $\mathrm{mg} \mathrm{C}^{-1} \mathrm{~L}$, and as component contribution to total fluorescence, \%) (Fig. 3b).

\subsection{Mixing model results}

Mixing model results suggested that peatland groundwater was the dominant input to lakes in fine-textured settings (average $f_{\mathrm{P}}=0.92 \pm 0.08$, average \pm 1 standard deviation of central estimates across lakes), while mineral soil groundwater made a substantial contribution to lakes in coarse-textured settings (average $f_{\mathrm{P}}=0.56 \pm 0.25$ ) (Table 1 ). The $95 \%$ confidence intervals of $f_{\mathrm{P}}$ central estimates for each lake resulting from uncertainties of the constants in the mixing model averaged $0.84-0.96$ for lakes in fine-textured settings and $0.41-0.74$ for lakes in coarse-textured settings. Given the higher DOC concentrations, peatland groundwater DOC were estimated to account for $98 \pm 2 \%$ of terrestrial DOC in- puts to lakes in fine-textured settings and $79 \pm 21 \%$ of inputs to lakes in coarse-textured settings.

Observed lake DOC concentrations were significantly lower than expected if DOC were to mix conservatively (37 \pm 14 versus $69 \pm 15 \mathrm{mg} \mathrm{CL}^{-1}$, respectively, across all lakes). After taking into account algal contribution to the lake DOC pool and evaporative concentration of the lake water volume, the mixing model estimated that $56 \pm 15 \%( \pm 1$ standard deviation of central estimates across lakes) of terrestrial DOC inputs to the lakes had been lost within the lakes. The average $95 \%$ confidence interval of the central estimates for individual within-lake losses of terrestrial DOC across lakes was 36-64\%. There were no differences in the estimated DOC losses either between lakes in fine- and coarsetextured settings or between lakes located within or outside the recent fire perimeter. Estimated within-lake losses of $A_{254}$ ( $71 \pm 12 \%$ and with average $95 \%$ confidence intervals between 58 and $76 \%$ ) were greater than the DOC losses (pairwise $t$ test, $n=30, p<0.001$ ), suggesting selective removal of aromatic DOC.

\section{Discussion}

\subsection{Links between mixing of terrestrial DOC sources and lake DOC composition and biodegradability}

Much of the variability in DOC composition among lakes could be attributed to the mixing of DOC from peatland groundwater and mineral soil groundwater sources. In other regions it has been shown that DOC aromaticity in rivers increases with increased peatland catchment cover (Ågren et al., 2008; Olefeldt et al., 2013a). However, in our study region it is difficult to assess lake water sources using ecosystem configuration within topographically delineated catchments due to deep and heterogenous glacial deposits and complex groundwater hydrology (Devito et al., 2005). For example, we observed large variability in lake DOC aromaticity even for lakes completely surrounded by peatlands (SUVA ranging between 1.3 and $2.9 \mathrm{~L} \mathrm{mg} \mathrm{C}^{-1} \mathrm{~m}^{-1}$ ). Instead, we used Ec as a conservative tracer to assess the relative contribution from different water sources, with lake water constituting a mix of mineral soil groundwater with high Ec and peatland groundwater with low Ec. The mixing model took into account that mineral groundwater in finetextured mineral soils has higher Ec than in coarse-textured soils (Ferone, 2001; Gibbons, 2005). Peatland groundwater contribution to lake water, $f_{\mathrm{P}}$, was strongly related to lake DOC composition, particularly SUVA, which indicates aromaticity, and PARAFAC components $C_{\mathrm{C}}$ and $C_{\mathrm{X}}$ that are associated with fluorescence of terrestrially derived humic and fulvic acids ( $R^{2}$ between 0.56 and 0.51 ). These DOC composition indices also had the largest differences between peatland and mineral soil DOC sources, further emphasizing that 
a mixing of terrestrial sources is a primary control on lake DOC composition.

The two primary sources of terrestrial DOC to lakes in the study region, peatland groundwater and mineral soil groundwater, differed both in terms of DOC composition and biodegradability. Peatland groundwater DOC had lower biodegradability than mineral soil groundwater DOC, possibly due to higher aromaticity (as indicated by SUVA), higher humic/fulvic acid contributions (PARAFAC components $C_{\mathrm{C}}$ and $C_{\mathrm{X}}$ ) and lower protein contribution to the DOC pool (PARAFAC component $C_{\mathrm{T}}$ ) (cf. Kalbitz et al., 2003a). Similar differences between DOC biodegradability and composition has also been observed in subarctic Alaska, where peatland thermokarst DOC had lower biodegradability along with lower protein-type fluorescence and higher SUVA than DOC samples from mineral soil groundwater springs (Balcarczyk et al., 2009).

Biodegradability and SUVA of DOC samples from organic soils, fresh litter and vegetation leachates have a strong negative relationship (cf. Kalbitz et al., 2003a). However, in this study we found only a weak negative relationship between dark incubation DOC losses and SUVA, and biodegradability remained relatively low even for mineral soil groundwater samples with very low SUVA. In a similar incubation experiment, leachates from organic soils with comparable SUVA to that of the mineral soil DOC in this study exhibited losses that were 5-10 times greater (Olefeldt et al., 2013b). Hence, DOC composition as determined through absorbance and fluorescence techniques cannot be used to predict DOC biodegradability universally. Several studies, including this study, suggest that relationships between biodegradability and DOC composition are altered or disappear when DOC composition has been affected by UV light or selective adsorption/desorption in mineral soils (Moran et al., 2000; Holmes et al., 2008; Roehm et al., 2009). Non-aromatic DOC compounds have weak absorbing and fluorescing properties, and are thus poorly characterized in optical DOC composition indices, yet may have a wide variability in biodegradability. For example, DOC in surface soil leachates has a high contribution of highly biodegradable aliphatic carbohydrates (Kalbitz et al., 2003a), while non-aromatic DOC in mineral soils is more likely derived from microbial exudations and selective adsorption/desorption processes (Kothawala et al., 2012a), and non-aromatic DOC following exposure to UV light is associated with transformed lignin compounds (Benner and Kaiser, 2011).

Lake DOC biodegradability was low for all lakes (ranging between 0.3 and $2.1 \%$ loss over 11 days, as measured by $\mathrm{CO}_{2}$ production) and was not related to observed DOC composition or the estimated relative contribution of mineral/peatland waters. Thus there was no indication that lake DOC with a greater contribution from mineral groundwater sources had higher biodegradability. A long-term dark incubation study found that initial decay of DOC from clearwater lakes was higher than for brown water lake DOC, but this difference disappeared after 5 months, and cumulative losses over $3.5 \mathrm{yr}$ were similar $(\sim 35 \%)$ across lakes regardless of initial DOC composition (Koehler et al., 2012). Since the lakes in our study region have long residence times, it is possible that initial differences in biodegradability, due to a variable mixing of DOC sources, have converged.

The mixing model estimated that on average across lakes, $54 \%$ (with average $95 \%$ confidence interval: 36-64\%) of the terrestrial DOC that reach the lakes had been lost to within-lake processes, causing mineralization or sedimentation. Although the mixing model was sensitive to its assumptions, there was a strong agreement among lakes with regards to the general magnitude of within-lake DOC losses. While we observed very low biodegradability of lake DOC samples in our short 11-day dark incubations, long-term incubations of lake DOC suggest that microbial degradation in lakes with long water residence time could be responsible for the majority of within-lake terrestrial DOC losses (e.g. $35 \%$ losses over $3.5 \mathrm{yr}$ incubations, Koehler et al., 2012). However, both short- and long-term dark incubations only cause minor changes in DOC composition, including minor increases in aromaticity and humic/fulvic acid fluorescence (Kothawala et al., 2012b; Olefeldt et al., 2013b). Thus, microbial degradation alone does not explain the observation in this study where even lakes completely dominated by peatland DOC inputs had lower aromaticity and lower $C_{\mathrm{C}}$ and $C_{\mathrm{X}}$ fluorescence than observed in peatland groundwater DOC.

\subsection{Support for significant contribution of UV-mediated processes to within-lake loss of terrestrial DOC}

While incubation losses under dark conditions were low for peatland DOC, large losses were observed under UV conditions (8-19\% over 11 days). High DOC losses during UV incubations were linked to high aromaticity as indicated by SUVA. Initial sample SUVA was particularly strongly related to the difference between incubation losses during UV and dark and dark incubations. For mineral soil DOC with low initial SUVA this meant that DOC losses were greater during dark than UV incubations. Reduced DOC loss during UV incubations for samples of low aromaticity has previously been observed (Tranvik and Bertilsson, 2001), possibly linked to the damaging effects of UV light on microbes in the absence of UV attenuation. Lake DOC had characteristics intermediate to peatland well and mineral soil well DOC with regards to both composition and reactivity. However, while mineralization was found to completely dominate DOC losses in lake samples, mineralization and the production of particulate organic carbon were found to contribute equally to DOC losses from peatland samples. Peatland DOC thus appears to have aromatic fractions that will readily flocculate once first exposed to UV light (von Wachenfeldt et al., 2008), constituting a potentially important pathway for lake organic matter sediment accumulation. 
Photochemical transformations are related to the total amount of absorbed UV radiation (Bertilsson and Tranvik, 2000). Because DOC concentrations were standardized at the start of the incubations, samples with higher SUVA in our incubations also had higher $A_{254}$, and therefore absorbed more UV light. Thus DOC concentration and composition may not be related to the rate of UV-mediated DOC removal in lakes, where DOC concentrations are variable, but rather regulate the depth over which UV processes occur and which fractions of the DOC pool that are affected. In humic freshwater lakes, UV attenuation is strongly linked to DOC concentration with approximate depths for $99 \%$ attenuation of UV-B radiation at 4 and $40 \mathrm{~cm}$ for lakes with 60 and $10 \mathrm{mg} \mathrm{CL}^{-1}$ DOC concentrations, respectively (Arts et al., 2000). Although UV-mediated removal is restricted to shallow surface layers, the substantially increased rates of degradation during UV incubations, along with the fact that most of the sampled lakes are shallow $(\sim 1-2 \mathrm{~m})$ and remain well mixed throughout summers, suggest that UV-mediated removal may still have the potential to significantly contribute to within-lake losses of terrestrial DOC, particularly of highly aromatic DOC.

Observed changes in DOC composition during UV incubations were consistent with previous studies that have shown that photodegradation acts primarily on aromatic DOC, causing both mineralization, flocculation (von Wachenfeldt et al., 2008) and production of LMW acids that subsequently become available for microbial degradation (Bertilsson and Tranvik, 2000; Obernosterer and Benner, 2004; Brinkmann, 2003). Peatland DOC exhibited substantial decreases in SUVA and PARAFAC components $C_{\mathrm{C}}$ and $C_{\mathrm{X}}$ (associated with HMW humic and fulvic acids) but increases in $C_{\mathrm{T}}$ (associated with amino acids) during UV incubations. As a result of these changes, peatland DOC composition at the end of the UV incubations came to resemble the initial composition of lake DOC, particularly for profiles of the PARAFAC components.

With longer water residence times of terrestrial DOC in lakes, we expected to find evidence of greater within-lake removal. The study was carried out in a sub-humid region where lake evaporation is an important part of the water balance of lakes, even in groundwater flow-through lake systems (Smerdon et al., 2005; Ferone and Devito, 2004). Variability in observed evaporative enrichment of $\delta^{18} \mathrm{O}$ and $\delta \mathrm{D}$ in lakes relative to terrestrial water sources can therefore be assumed to serve as a relative measure of lake water residence times. Lakes with more highly enriched $\delta^{18} \mathrm{O}$, indicating longer residence time, also had DOC composition indices consistent with shifts observed during UV incubations of peatland DOC, including lower SUVA, $C_{\mathrm{C}}$ and $C_{\mathrm{X}}$. Thus, observed lake DOC composition appeared to be a function of both the relative contribution from different terrestrial sources along with a variable degree of within-lake photochemical transformations related to residence time. The UV incubation showed that such changes in DOC composition were concurrent with significant DOC losses.

Together, our results support a substantial contribution from UV-mediated degradation of aromatic DOC for withinlake losses of terrestrial DOC. The mixing model suggests that peatland DOC dominated lake DOC inputs, and the incubation experiment showed that while peatland DOC had very low biodegradability, it was readily lost during UV incubation. The mixing model suggested that more than half of terrestrially derived DOC had been lost within lakes, but also indicated that losses of $A_{254}$ had been even greater. Preferential loss of $A_{254}$ to DOC was also observed during UV incubations as indicated by decreasing SUVA, but contrasts with observations of increasing SUVA during both short- and long-term dark DOC incubations (Kothawala et al., 2012b; Olefeldt et al., 2013b). The changes in DOC composition indicated by PARAFAC analysis during UV incubations were also consistent with the observed patterns in DOC composition for lakes with greater evaporative isotope enrichment, assumed to be linked to longer water residence times and thus greater UV exposure. Previous studies have estimated that UV-mediated processes only contribute $\sim 10 \%$ of total epilimnetic respiration in boreal humic lakes (Graneli et al., 1996; Jonsson et al., 2001). However, these estimates include $\mathrm{CO}_{2}$ emissions due to the rapid turnover of highly biodegradable autochthonous DOC, and may therefore underestimate the importance of UV-mediated degradation of terrestrial DOC. Further, the lakes in our study region have characteristics that are likely to enhance UV-mediated losses over microbial processes alone compared to other boreal regions. This includes shallow water depths $(0.5-5 \mathrm{~m})$ that promote mixing and exposure of DOC to UV light, along with a sub-humid climate that in combination with regional hydrogeology results in lakes primarily receiving highly aromatic peatland DOC, which is poorly biodegradable but susceptible to photodegradation. Hence, our study region may represent a boreal region where UV-mediated processes are relatively more important for within-lake losses of terrestrial DOC than in other regions. Given that shallow lakes, extensive peatlands and a sub-humid climate characterizes much of the boreal and taiga plains of western Canada, our study suggests that UV-mediated processes need to be considered as important drivers of aquatic $\mathrm{C}$ cycling in large boreal regions.

\subsection{Influence of wildfire on terrestrial DOC sources and aquatic DOC cycling.}

Wildfire has been found to have varying short-term (1-10 yr after fire) impacts on catchment DOC export and lake DOC concentrations and biodegradability in different regions. While Alaskan catchments had decreased DOC export following wildfire (Betts and Jones, 2009), no change in DOC export was found for catchments on the boreal shield in Quebec (Lamontagne et al., 2000). Comparative studies in 
the foothills and subarctic ecoregions of central and northern Alberta, respectively, found that average DOC concentrations were $40-50 \%$ higher in lakes with recently burned surroundings compared to nearby lakes with unburned surroundings (McEachern et al., 2000; Allen et al., 2003). In our study region there was no influence of wildfire on lake DOC concentrations before and after the fire, but URSA differs significantly from the other studied regions in Alberta with regards to topography, dominant terrestrial ecosystems and runoff generation. Although DOC concentrations in lakes on the boreal shield of Quebec were also not found to be influenced by wildfire (Carignan et al., 2000), Marchand et al. (2009) found that wildfire increased lake DOC biodegradability in Quebec, something we did not observe in this study. It remains an open question as to whether or not these contrasting results can be reconciled into a single framework by considering regional characteristics (e.g. climatic controls on hydrology), local characteristics (e.g. surface geology and dominant ecosystems) and fire characteristics (e.g. severity and timing) (cf. Pinoul-Allel et al., 2002; Devito et al., 2005; Turetsky et al., 2010). The design of this study allows for a discussion on how regional and local characteristics may have contributed to the lack of an impact of fire on lake DOC concentration, composition and reactivity.

The strongest potential for wildfire to alter linkages between terrestrial and aquatic $\mathrm{C}$ cycling in the study region is by altering the magnitude or composition of peatland DOC export. Upland ecosystems in the study region rarely generate hillslope runoff (Redding and Devito, 2008), and are thus assumed to contribute negligible DOC inputs to lakes. In the absence of DOC export from forested hillslopes, the mixing model suggested that peatlands dominated terrestrial DOC export to lakes in fine-textured settings, and was only complemented by DOC from mineral soil groundwater to lakes in coarse-textured settings. The composition and biodegradability of mineral soil DOC was not found to be altered by wildfire in this study, likely due to the processes of selective adsorption, degradation and desorption that affect DOC composition as it slowly cycles downwards in mineral soils (Kaiser and Kalbitz, 2012). In contrast, this study showed that nearsurface peatland pore water had higher SUVA in burned than unburned peatlands, which is consistent with results from a recent study that showed that DOC leached from surface peat collected in burned peatlands had higher aromaticity and lower biodegradability than leachates from unburned bogs (Olefeldt et al., 2013b). Both the production of highly aromatic char and the removal of live Sphagnum moss, which produce highly labile DOC (Wickland et al., 2007), could explain the change in DOC composition in surficial soils. However, the difference in DOC composition in peat profiles between burned and unburned peatland was smaller or insignificant for pore-water samples at or below the water table, and we observed no differences in DOC concentration or composition between peatland wells located within and outside the recent fire. Peatland runoff generation preferentially occurs close to the water table, and since water table position in the region often is low due to dry conditions, peatland export of DOC is likely dominated by DOC originating from deeper peat layers where the recent fire was not found to alter its composition.

The lack of an observed difference in DOC composition at depth between burned and unburned peatlands does not imply that char does not contribute DOC for downstream export. It is likely that char layers present in the peat strata, associated with historical wildfires from the course of the peatland development, contribute highly aromatic DOC to the soil DOC pool in the study region (Hockaday et al., 2007). DOC export derived from such deeper char sources should, however, be regarded as a long-term influence of wildfire and not a pulse perturbation to terrestrial-aquatic linkage from recent wildfires that this study was designed to detect.

While we observed a large variation among the sampled lakes with regards to DOC concentration, composition and biodegradability, none of this variation could be attributed to lakes located within or outside the recent fire perimeter. Hence, although wildfire created a potential for altered downstream export by altering near-surface peatland DOC sources, the lack of a signal in lake DOC composition suggests that peatland export is dominated by DOC from deeper peat layers at or below the water table that were not altered by the recent wildfire. Our results therefore suggest that it is necessary to consider both the impact of fire on terrestrial sources and their hydrological connectivity to downstream aquatic ecosystems in order to anticipate changes to aquatic $\mathrm{C}$ loading and cycling.

\section{Conclusions}

Here we characterized the composition and reactivity of both terrestrial sources and aquatic DOC in a peatland-rich region of the Boreal Plains ecoregion in western Canada recently affected by wildfire. Our study suggests that wildfire alters DOC composition in surficial pore water in peatlands by increasing its aromaticity, but it also suggests that this effect is not apparent in deeper peat layers at or below the water table. Our results suggest that deeper peat layers were the dominant source of terrestrial DOC export to lakes, likely due to regional characteristics such as sub-humid climate, thick overburden and widespread peatlands. The dominance of DOC from deep peat layers regardless of fire history likely explain the absence of any difference in DOC concentration, composition and bio/photo-reactivity between lakes located within and outside the recent fire perimeter. To significantly affect terrestrial DOC export composition and magnitude, we speculate that it is necessary for wildfire to remove enough organic material to alter DOC sources at the depth of the dominant flow paths. Thus regions with thinner organic soils and shallower dominant flow paths or regions that experience severe burning will be more likely to exhibit altered DOC 
export following wildfire. Hence, while catchments with upland forest have exhibited decreased DOC export following wildfire (Betts and Jones, 2009), our results suggest that peatland DOC export is less likely to be impacted by burning. This resistance of peatland DOC export to fire disturbance needs to be taken into account in biogeochemical processes models of DOC loading to aquatic ecosystems (Kicklighter et al., 2013). Rather than a short-term influence of wildfire, char from historical wildfires is likely to contribute to peatland DOC export over longer temporal scales. And while char often is considered biogeochemically stable in soils, partly due to its high contribution of condensed aromatic structure, we show that once highly aromatic and poorly biodegradable DOC from deep peat layers reach aquatic ecosystems, it can readily be mineralized through UV-mediated processes.

The mineralization and sedimentation of terrestrial DOC in lakes represents an important aspect of the global $\mathrm{C}$ cycle. Our central estimate for within-lake removal of terrestrially exported DOC was greater than $50 \%$, and our results suggest that UV-mediated processes play a very important role in the mineralization and sedimentation of terrestrial DOC in the studied lakes. UV-mediated processes are believed to be particularly important in our study region (Boreal Plains) due to both the composition and observed reactivity of the dominant terrestrial DOC sources and the high UV light availability in the typically shallow lakes. While aquatic $\mathrm{C}$ cycling and food webs have been proposed to be primarily linked to inputs of highly biodegradable DOC associated with recent terrestrial primary production (Berggren et al., 2010), it has been found that bacterially respired $\mathrm{CO}_{2}$ in boreal lakes can originate from material that is several thousand years old (McCallister and del Giorgio 2012). Our study suggests that poorly biodegradable DOC fractions, e.g. those associated with old peat or char deposits, may contribute significantly to aquatic $\mathrm{C}$ cycling following exposure to UV light and thereby contribute to aged lake $\mathrm{CO}_{2}$ emissions. This temporal break between terrestrial productivity and its connection to aquatic $\mathrm{C}$ cycling is likely to have contributed to the lack of a response of aquatic $\mathrm{C}$ cycling to wildfire in this study. Conversely, disturbances that primarily affect the hydrological connectivity of aged organic material, e.g. permafrost thaw, could thus potentially affect aquatic $\mathrm{C}$ cycling through $\mathrm{UV}$-mediated degradation (Cory et al., 2013). While much remains to be learned, our study highlights that our understanding of links between terrestrial and aquatic $\mathrm{C}$ cycling will be improved upon by untangling the relative contribution of dark microbial and UV-mediated degradation processes in aquatic ecosystems and its dependency on the age, composition and hydrological connectivity of terrestrial DOC sources.

\section{Supplementary material related to this article is available online at http://www.biogeosciences.net/10/ 6247/2013/bg-10-6247-2013-supplement.pdf.}

Acknowledgements. Support was provided to M. R. Turetsky through NSERC funding and by the Ontario Ministry of Research and Innovation through an ERA award, and through NSERC-CRD (CRDPJ 238050-00) and Syncrude Canada Ltd (\#4410012045) grants to K. J. Devito. Helpful assistance with field- and lab work was provided by Abra Martin, Matthew McGoveran, Carolyn Gibson, Arielle Garrett, Chandra London and Mika Little-Devito, and by Carolynn Forsyth for camp facilities at ArtistInn. We thank Christian Blodau for use of field equipment.

Edited by: B. A. Bergamaschi

\section{References}

Ågren, A., Buffam, I., Berggren, M., Bishop, K., Jansson, M., and Laudon, H.: Dissolved organic carbon characteristics in boreal streams in a forest-wetland gradient during the transition between winter and summer, J. Geophys. Res.-Biogeo., 113, G03031, doi:10.1029/2007jg000674, 2008.

Alberta Sustainable Resource Development, Government of Alberta: Historical wildfire perimeters of Alberta, available at: http://srd.alberta.ca/Wildfire/WildfireStatus/ HistoricalWildfireInformation/SpatialWildfireData.aspx), (last access: 1 October 2013), 2013.

Algesten, G., Sobek, S., Bergström, A. K., Ågren, A., Tranvik, L. J., and Jansson, M.: Role of lakes for organic carbon cycling in the boreal zone, Glob. Change Biol., 10, 141-147, 2004.

Allen, E. W., Prepas, E. E., Gabos, S., Strachan, W., and Chen, W.: Surface water chemistry of burned and undisturbed watersheds on the Boreal Plain: an ecoregion approach, J. Environ. Eng. Sci., 2, S73-S86, doi:10.1139/s03-035, 2003.

Arts, M. T., Robarts, R. D., Kasai, F., Waiser, M. J., Tumber, V. P., Plante, A. J., Rai, H., and de Lange, H. J.: The attenuation of ultraviolet radiation in high dissolved organic carbon waters of wetlands and lakes on the northern Great Plains, Limnol Oceanogr., 45, 292-299, 2000.

Bade, D. L., Carpenter, S. R., Cole, J. J., Pace, M. L., Kritzberg, E., Van de Bogert, M. C., Cory, R. M., McKnight, D. M.: Sources and fate of dissolved organic carbon in lakes as determined by whole-lake carbon isotope additions, Biogeochemistry, 84, 115129, doi:10.1007/s10533-006-9013-y, 2007.

Balcarczyk, K. L., Jones, J. B., Jaffe, R., and Maie, N.: Stream dissolved organic matter bioavailability and composition in watersheds underlain with discontinuous permafrost, Biogeochemistry, 94, 255-270, doi:10.1007/s10533-009-9324-x, 2009.

Bayley, S. E., Creed, I. F., Sass, G. Z., and Wong, A. S.: Frequent regime shifts in trophic states in shallow lakes on the Boreal Plain: Alternative "unstable" states?, Limnol. Oceanogr., 52 , 2002-2012, doi:10.4319/lo.2007.52.5.2002, 2007.

Benner, R. and Kaiser, K.: Biological and photochemical transformations of amino acids and lignin phenols in riverine dissolved organic matter, Biogeochemistry, 102, 209-222, doi:10.1007/s10533-010-9435-4, 2011.

Berggren, M., Ström, L., Laudon, H., Karlsson, J., Jonsson, A., Giesler, R., Bergström, A.-K., and Jansson, M.: Lake secondary production fuelled by rapid transfer of low molecular weight organic carbon from terrestrial sources to aquatic consumers, Ecol. Lett., 13, 870-880, doi:10.1111/j.14610248.2010.01483.x, 2010. 
Bertilsson, S. and Tranvik, L. J.: Photochemical transformation of dissolved organic matter in lakes, Limnol. Oceanogr., 45, 753762,2000

Betts, E. F. and Jones, J. B.: Impact of Wildfire on Stream Nutrient Chemistry and Ecosystem Metabolism in Boreal Forest Catchments of Interior Alaska, Arct. Antarct. Alp. Res., 41, 407-417, doi:10.1657/1938-4246-41.4.407, 2009.

Brinkmann, T., Horsch, P., Sartorius, D., and Frimmel, F. H.: Photoformation of low-molecular-weight organic acids from brown water dissolved organic matter, Environ. Sci. Technol., 37, 41904198, doi:10.1021/es0263339, 2003.

Canadian Forest Service: National Fire Database - Agency FireData, Natural Resources Canada, Canadian Forest Service, Northern Forestry Centre, Edmonton, Alberta, http://cwfis.cfs. nrcan.gc.ca/en_CA/nfdb, (last access: 1 October 2013), 2011.

Carignan, R., D'Arcy, P., and Lamontagne, S.: Comparative impacts of fire and forest harvesting on water quality in Boreal Shield lakes, Can. J. Fish. Aquat. Sci., 57, 105-117, 2000.

Certini, G.: Effects of fire on properties of forest soils: a review, Oecologia, 143, 1-10, doi:10.1007/s00442-004-1788-8, 2005.

Coble, P. G.: Characterization of marine and terrestrial DOM in seawater using excitation emission matrix spectroscopy, Mar. Chem., 51, 325-346, doi:10.1016/0304-4203(95)00062-3, 1996.

Cory, R. M., Crump, B. C., Dobkowski, J. A., and Kling, G. W.: Surface exposure to sunlight stimulates $\mathrm{CO}_{2}$ release from permafrost soil carbon in the Arctic, P. Natl. Acad. Sci. USA, 110, 3429-3434, doi:10.1073/pnas.1214104110, 2013.

Creed, I. F., Beall, F. D., Clair, T. A., Dillon, P. J., and Hesslein, R. H.: Predicting export of dissolved organic carbon from forested catchments in glaciated landscapes with shallow soils, Global Biogeochem. Cy., 22, GB4024, doi:10.1029/2008gb003294, 2008.

Devito, K., Creed, I., Gan, T., Mendoza, C., Petrone, R., Silins, U., and Smerdon, B.: A framework for broad-scale classification of hydrologic response units on the Boreal Plain: is topography the last thing to consider?, Hydrol. Process., 19, 1705-1714, doi:10.1002/hyp.5881, 2005.

EcoRegions Working Group: Ecoclimatic Regions of Canada, First Approximation, Ecological Land Classification Series, No 23, 119 pp., Environment Canada, Ottawa, 1989.

Fellman, J. B., Hood, E., and Spencer, R. G. M.: Fluorescence spectroscopy opens new windows into dissolved organic matter dynamics in freshwater ecosystems: A review, Limnol. Oceanogr., 55, 2452-2462, doi:10.4319/lo.2010.55.6.2452, 2010.

Fenton, M. M., Paulen, R. C., and Pawlowicz, J. G.: Surficial geology of the Lubicon Lake area, Alberta (NTS 84B/SW), Alberta Geological Survey, Edmonton, 2003.

Ferone, J.: Landscape controls of hydrologic function and phosphorous dynamics in two pond-wetland complexes on the mixedwood boreal plain, M.Sc. Thesis, Biological Sciences, University of Alberta, Edmonton, Alberta, 159 pp., 2001.

Ferone, J. M. and Devito, K. J.: Shallow groundwater-surface water interactions in pond-peatland complexes along a Boreal Plains topographic gradient, J. Hydrol., 292, 75-95, doi:10.1016/j.jhydrol.2003.12.032, 2004.

Flannigan, M., Stocks, B., Turetsky, M., and Wotton, M.: Impacts of climate change on fire activity and fire management in the circumboreal forest, Glob. Change Biol., 15, 549-560, doi:10.1111/j.1365-2486.2008.01660.x, 2009.
Gibbons, Z.: The influence of groundwater flow on phosphate dynamics in three riparian wetlands surrounding an outwash lake in northern Alberta, MSc thesis, Department of Biological Sciences, University of Alberta, Edmonton, Alberta, 95 pp., 2005.

Graneli, W., Lindell, M., and Tranvik, L.: Photo-oxidative production of dissolved inorganic carbon in lakes of different humic content, Limnol. Oceanogr., 41, 698-706, 1996.

Hargreaves, G. H. and Samani, Z. A.: Estimation of potential evapotranspiration, Journal of Irrigation and Drainage Division, Proceedings of the American Society of Civil Engineers, 108, 223$230,1982$.

Hockaday, W. C., Grannas, A. M., Kim, S., and Hatcher, P. G.: The transformations and mobility of charcoal in fireimpacted watersheds, Geochim. Cosmochim. Ac., 71, 34323445, doi:10.1016/j.gca.2007.02.023, 2007.

Holmes, R. M., McClelland, J. W., Raymond, P. A., Frazer, B. B., Peterson, B. J., and Stieglitz, M.: Lability of DOC transported by Alaskan rivers to the Artic Ocean, Geophys. Res. Lett., 35, L03402, doi:10.1029/2007GL032837, 2008.

Jonsson, A., Meili, M., Bergström, A. K., and Jansson, M.: Wholelake mineralization of allochthonous and autochthonous organic carbon in a large humic lake (Ortrasket, N. Sweden), Limnol. Oceanogr., 46, 1691-1700, 2001.

Kaiser, K. and Kalbitz, K.: Cycling downwards - dissolved organic matter in soils, Soil Biol. Biochem., 52, 29-32, doi:10.1016/j.soilbio.2012.04.002, 2012.

Kalbitz, K., Schmerwitz, J., Schwesig, D., and Matzner, E.: Biodegradation of soil-derived dissolved organic matter as related to its properties, Geoderma, 113, 273-291, doi:10.1016/S0016-7061(02)00365-8, 2003a.

Kalbitz, K., Schwesig, D., Schmerwitz, J., Kaiser, K., Haumaier, L., Glaser, B., Ellerbrock, R., and Leinweber, P.: Changes in properties of soil-derived dissolved organic matter induced by biodegradation, Soil Biol. Biochem., 35, 1129-1142, doi:10.1016/S00380717(03)00165-2, 2003b.

Kicklighter, D. W., Hayes, D., McClelland, J., Peterson, B. J., McGuire, A. D., and Melillo, J. M.: Insights and issues with simulating terrestrial DOC export of arctic river networks, Ecol. Appl., doi:10.1890/11-1050.1, in press, 2013.

Koehler, B., von Wachenfeldt, E., Kothawala, D., and Tranvik, L. J.: Reactivity continuum of dissolved organic carbon decomposition in lake water, J. Geophys. Res.-Biogeo., 117, G01024, doi:10.1029/2011jg001793, 2012.

Kothawala, D. N., Roehm, C., Blodau, C., and Moore, T. R.: Selective adsorption of dissolved organic matter to mineral soils, Geoderma, 189, 334-342, 2012a.

Kothawala, D. N., von Wachenfeldt, E., Koehler, B., and Tranvik, L. J.: Selective loss and preservation of lake water dissolved organic matter fluorescence during long-term dark incubations, Sci. Total Environ., 433, 238-246, doi:10.1016/j.scitotenv.2012.06.029, 2012b.

Lamontagne, S., Carignan, R., D’Arcy, P., Prairie, Y. T., and Pare, D.: Element export in runoff from eastern Canadian Boreal Shield drainage basins following forest harvesting and wildfires, Can. J. Fish. Aquat. Sci., 57, 118-128, 2000.

Marchand, D., Prairie, Y. T., and del Giorgio, P. A.: Linking forest fires to lake metabolism and carbon dioxide emissions in the boreal region of Northern Quebec, Glob. Change Biol., 15, 28612873, doi:10.1111/j.1365-2486.2009.01979.x, 2009. 
Marshall, I. B., Schut, P., and Ballard, M.: A National Ecological Framework for Canada: Attribute Data. Environmental Quality Branch, Ecosystems Science Directorate, Environment Canada and Research Branch, Agriculture and AgriFood Canada, Ottawa, http://sis.agr.gc.ca/cansis/nsdb/ecostrat/ 1999report/index.html, (last access: 26 February 2013), 1999.

Mattsson, T., Kortelainen, P., and Raike, A.: Export of DOM from boreal catchments: impacts of land use cover and climate, Biogeochemistry, 76, 373-394, doi:10.1007/s10533-005-6897$\mathrm{x}, 2005$.

McCallister, S. L. and del Giorgio, P. A.: Evidence for the respiration of ancient terrestial organic $\mathrm{C}$ in northern temperate lakes and streams, P. Natl. Acad. Sci. USA, 109, 16963-16968, doi:10.1073/pnas.1207305109, 2012.

McEachern, P., Prepas, E. E., Gibson, J. J., and Dinsmore, W. P.: Forest fire induced impacts on phosphorus, nitrogen, and chlorophyll a concentrations in boreal subarctic lakes of northern Alberta, Can. J. Fish. Aquat. Sci., 57, 73-81, 2000.

Moran, M. A., Sheldon, W. M., and Zepp, R. G.: Carbon loss and optical property changes during long-term photochemical and biological degradation of estuarine dissolved organic matter, Limnol. Oceanogr., 45, 1254-1264, 2000.

Neff, J. C., Harden, J. W., and Gleixner, G.: Fire effects on soil organic matter content, composition, and nutrients in boreal interior Alaska, Can. J. For. Res.-Rev. Can. Rech. For., 35, 2178 2187, doi:10.1139/x05-154, 2005.

Obernosterer, I. and Benner, R.: Competition between biological and photochemical processes in the mineralization of dissolved organic carbon, Limnol. Oceanogr., 49, 117-124, 2004.

Ohno, T.: Fluorescence inner-filtering correction for determining the humification index of dissolved organic matter, Environ. Sci. Technol., 36, 742-746, doi:10.1021/es0155276, 2002.

Olefeldt, D., Roulet, N., Giesler, R., and Persson, A.: Total waterborne carbon export and DOC composition from ten nested subarctic peatland catchments - importance of peatland cover, groundwater influence, and inter-annual variability of precipitation patterns, Hydrol. Process., 27, 2280-2294, doi:10.1002/hyp.9358, 2013a.

Olefeldt, D., Turetsky, M., and Blodau, C.: Altered composition and microbial versus UV-mediated degradation of dissolved organic matter in boreal soils following wildfire, Ecosystems, in press, doi:10.1007/s10021-013-9691-y, 2013b.

Pinel-Alloul, B., Prepas, E., Planas, D., Steedman, R., and Charette, T.: Watershed impacts of logging and wildfire: Case studies in Canada, Lake Reserv. Manage., 18, 307-318, 2002.

Plummer, L. N. and Busenberg, E.: The solubilities of calcite, aragonite and vaterite in $\mathrm{CO}_{2}-\mathrm{H}_{2} \mathrm{O}$ solutions between 0 and $90^{\circ} \mathrm{C}$, and an evaluation of the aquous model for the system $\mathrm{CaCO}_{3}$ $\mathrm{CO}_{2}-\mathrm{H}_{2} \mathrm{O}$, Geochim. Cosmochim. Ac., 46, 1011-1040, 1982.

Prairie, Y. T.: Carbocentric limnology: looking back, looking forward, Can. J. Fish. Aquat. Sci., 65, 543-548, doi:10.1139/f08011, 2008.

Redding, T. E. and Devito, K. J.: Lateral flow thresholds for aspen forested hillslopes on the Western Boreal Plain, Alberta, Canada, Hydrol. Process., 22, 4287-4300, doi:10.1002/hyp.7038, 2008.

Roehm, C. L., Giesler, R., and Karlsson, J.: Bioavailability of terrestrial organic carbon to lake bacteria: The case of a degrading permafrost mire complex, J. Geophys. Res.-Biogeo., 114, G03006, doi:10.1029/2008JG000863, 2009.
Sass, G. Z. and Creed, I. F.: Characterizing hydrodynamics on boreal landscapes using archived synthetic aperture radar imagery, Hydrol. Process., 22, 1687-1699, doi:10.1002/hyp.6736, 2008.

Sass, G. Z., Creed, I. F., Bayley S. E., and Devito K. J.: Interannual variability in trophic status of shallow lakes on the Boreal Plain: Is there a climate signal?, Water Resour. Res., 44, W08443, doi:10.1029/2007WR006310, 2008.

Schindler, D. W., Bayley, S. E., Parker, B. R., Beaty, K. G., Cruikshank, D. R., Fee, E. J., Schindler, E. U., and Stainton, M. P.: The effects of climatic warming on the properties of boreal lakes and streams at the Experimental Lakes Area, northwestern Ontario, Limnol. Oceanogr., 41, 1004-1017, 1996.

Smerdon, B. D., Devito, K. J., and Mendoza, C. A.: Interaction of groundwater and shallow lakes on outwash sediments in the sub-humid Boreal Plains of Canada, J. Hydrol., 314, 246-262, doi:10.1016/j.jhydrol.2005.04.001, 2005.

Smerdon, B. D., Mendoza, C. A., and Devito, K. J.: Influence of subhumid climate and water table depth on groundwater recharge in shallow outwash aquifers, Water Resour. Res., 44, W08427, doi:10.1029/2007wr005950, 2008.

Sobek, S., Tranvik, L. J., and Cole, J. J.: Temperature independence of carbon dioxide supersaturation in global lakes, Global Biogeochem. Cy., 19, Gb2003, doi:10.1029/2004gb002264, 2005.

Stedmon, C. A. and Bro, R.: Characterizing dissolved organic matter fluorescence with parallel factor analysis: a tutorial, Limnol. Oceanogr.-Meth., 6, 572-579, 2008.

Stubbins, A., Niggemann, J., and Dittmar, T.: Photo-lability of deep ocean dissolved black carbon, Biogeosciences, 9, 1661-1670, doi:10.5194/bg-9-1661-2012, 2012.

Tranvik, L. J. and Bertilsson, S.: Contrasting effects of solar UV radiation on dissolved organic sources for bacterial growth, Ecol. Lett., 4, 458-463, doi:10.1046/j.1461-0248.2001.00245.x, 2001.

Tranvik, L. J., Downing, J. A., Cotner, J. B., Loiselle, S. A., Striegl, R. G., Ballatore, T. J., Dillon, P., Finlay, K., Fortino, K., Knoll, L. B., Kortelainen, P. L., Kutser, T., Larsen, S., Laurion, I., Leech, D. M., McCallister, S. L., McKnight, D. M., Melack, J. M., Overholt, E., Porter, J. A., Prairie, Y., Renwick, W. H., Roland, F., Sherman, B. S., Schindler, D. W., Sobek, S., Tremblay, A., Vanni, M. J., Verschoor, A. M., von Wachenfeldt, E., and Weyhenmeyer, G. A.: Lakes and reservoirs as regulators of carbon cycling and climate, Limnol. Oceanogr., 54, 2298-2314, 2009.

Turetsky, M. R., Kane, E. S., Harden, J. W., Ottmar, R. D., Manies, K. L., Hoy, E., and Kasischke, E. S.: Recent acceleration of biomass burning and caron losses in Alaskan forests and peatlands, Nat. Geosci., 4, 27-31, doi:10.1038/NGEO1027, 2010.

Vogwill, R.: Hydrogeology of the Lesser Slave Lake area, Alberta, Edmonton AB, Alberta Research Council, 1978.

von Wachenfeldt, E., Sobek, S., Bastviken, D., and Tranvik, L. J.: Linking allochthonous dissolved organic matter and boreal lake sediment carbon sequestration: The role of light-mediated flocculation, Limnol. Oceanogr., 53, 2416-2426, 2008.

Wassenaar, L. I., Hendrey, M. J., Chostner, V. L., and Lis, G. P.: High resolution pore water $\delta^{2} \mathrm{H}$ and $\delta^{18} \mathrm{O}$ measurements by $\mathrm{H}_{2} \mathrm{O}_{\text {(liquid) }}-\mathrm{H}_{2} \mathrm{O}_{\text {(vapour) }}$ equilibration laser spectroscopy, Environ. Sci. Technol., 42, 9262-9267, doi:10.1021/es802065s, 2008.

Weishaar, J. L., Aiken, G. R., Bergamaschi, B. A., Fram, M. S., Fujii, R., and Mopper, K.: Evaluation of specific ultraviolet absorbance as an indicator of the chemical composition and reactiv- 
ity of dissolved organic carbon, Environ. Sci. Technol., 37, 47024708, doi:10.1021/Es030360x, 2003.

Weyhenmeyer, G. A., Fröberg, M., Karltun, E., Khalili, M., Kothawala, D., Temnerud, J., and Tranvik, L. J.: Selective decay of terrestrial organic carbon during transport from land to sea, Glob. Change Biol., 18, 349-355, doi:10.1111/j.13652486.2011.02544.x, 2012.
Wickland, K. P., Neff, J. C., and Aiken, G. R.: Dissolved organic carbon in Alaskan boreal forest: Sources, chemical characteristics, and biodegradability, Ecosystems, 10, 1323-1340, doi:10.1007/s10021-007-9101-4, 2007. 